\title{
Derailment study of railway cargo vehicles using a Response Surface Methodology
}

\author{
J.C. Pagaimo ${ }^{1}$, H. Magalhães ${ }^{1,2}$, J.N. Costa $^{1}$, J. Ambrósio $^{1}$ \\ ${ }^{1}$ IDMEC, Instituto Superior Técnico, Universidade de Lisboa, Lisboa, Portugal, \\ \{joao.pagaimo,joao.n.costa,jorge.ambrosio\}@tecnico.ulisboa.pt \\ ${ }^{2}$ Institute of Railway Research, School of Computing and Engineering, University of Huddersfield, UK \\ h.magalhaes@hud.ac.uk
}

\begin{abstract}
Railway bogies of the Y25 family are the most common type of bogies used in freight wagons in Europe. Their widespread use is associated with their low cost and low maintenance requirements. However, this family of bogies presents poor curving performance and a history of derailments. Although numerical simulations are a powerful tool to study railway dynamics, derailment scenarios involve complex operational and vehicle conditions that increase the multivariate aspect of the problem. Thus, simulating all possible scenario variants is unfeasible from a computational point of view due to limitations of time and computational resources. This paper proposes an approach based on a Response Surface Methodology to study the combined influence of uncertain parameters on the derailment potential of a railway vehicle running in realistic conditions. A case study of a real derailment is used to demonstrate the potential of this approach. A set of scenario configurations is identified using a Design of Experiments approach, and each one of them is simulated on the commercial software VAMPIRE. Then, the response surface functions of the quantities used to assess derailment are generated, and the conditions that maximise the derailment potential are identified. The results reveal a combination of asymmetric loading, excessive speed, and failure of a Lenoir link may cause extreme wheel unloading in the study developed. This work reveals the advantages of using a Response Surface Methodology to identify the conditions that maximise the derailment potential.
\end{abstract}




\section{Keywords}

Railway dynamics; Freight wagon; Derailment assessment; Vehicle modelling; Vehicle loading; Design of Experiments.

\section{Introduction}

Bogies of the Y25 family, such as the Y21, Y25, Y27 and Y33, are widely used in freight wagons in Europe. These bogies are developed to offer a low-cost, low-weight and lowmaintenance alternative to other bogie designs. However, this family of bogies presents poor running performance and has a history of derailments. While it is not feasible to overhaul the entire family of bogies, it is possible to assess the safety limits of the wagons equipped with these bogies. Assessing the derailment potential of a freight vehicle requires an understanding of the combined effects of the loading characteristics, condition of the suspension elements, and the operational context.

The railway dynamics involves the interaction between two subsystems that compose the railway systems: the rolling stock and the track [1,2]. Freight vehicles must ensure the protection of the cargo at the medium speed range, without the same comfort requirements as passenger vehicles. Therefore, friction-damped suspensions [3] are commonly used in freight wagons to reduce maintenance costs, at the expense of vehicle stability [4,5]. The primary suspension of the Y25 bogie connects the wheelsets to the bogie frame and consists of a combination of friction dampers and Lenoir links that play a key role in the dynamic behaviour of the bogie. [6-8]. The railway track supports and guides the vehicle through the interaction between the wheel and the rail [1]. The track layout is described by a succession of straight and curved sections connected by transition curves. Due to construction and degradation the track presents track irregularities, which are the deviations between the nominal geometry and the 
existing track layout. The track irregularities excite the vehicle, have a major impact on its dynamic behaviour, and are often responsible for deficient vehicle running [2,9-12].

The multibody methodology allows modelling the vehicle and the track and simulating their mutual interaction, to obtain the vehicle response and the associated wheel-rail contact forces $[13,14]$. Multibody simulations are widely used to appraise safety against derailment [1518], virtual homologation [15,19], wear [20], comfort assessment [21], sensitivity of the vehicle with respect to design and operation parameters [11,22] and to support the vehicle design process [13]. Better predictive multibody models are being obtained by using a more realistic description of the wheel-rail interface [23] or new and more advanced wheel-rail contact models [24-26]. The benefits and accuracy of multibody models of railway systems are well demonstrated experimentally [27]. Various commercial software such as VAMPIRE, VI-RAIL(ADAMS), SIMPACK and NUCARS have been developed to support the industry in the context of design and analysis, besides a good number of in-house software such as MUBODyn [24-26,28-30].

Past railway accidents motivated engineers to investigate the causes of derailment and to develop standards to improve the running safety of railway vehicles. The wagon loading motivated Di Galleonardo et al. to analyse the impact of sloshing on the derailment potential of a tanker wagon equipped with Y25 [18]. The particular effect of sloshing on the hunting of freight wagons has been addressed in [31]. More sophisticated representations of the railway track also contribute to a better characterisation of the phenomena [30]. These studies show that the mechanisms that trigger the start of derailment are complex. Most frequently, derailments are the combined result of several effects [17]. A good number of other works by different research groups explore various sources for derailment and different models to evaluate such derailment scenarios [32-34]. Common root causes leading to derailment are faulty vehicle and track conditions, possibly related to defective maintenance and management, poor vehicle-track compatibility, human factors such as errors of drivers and other personnel, and adverse 
environmental conditions. Several criteria have been developed to evaluate the derailment potential of railway vehicles. In order to mitigate these factors, railway systems rely extensively on regulations, standards, technical specifications and procedures, to guarantee the safety of the operations. Standards EN 14363 [35] and UIC 518 [36] regulate the testing and numerical simulations required for the acceptance of the running behaviour of railway vehicles.

Statistical tools are becoming increasingly popular in the fields of economics, sociology, demographics, natural sciences as well as engineering, allowing for the study of phenomena for which the analytical solution is unknown or unfeasible. The Response Surface Methodology (RSM) is a tool that allows the construction of a statistical model that provides a prediction of the behaviour of a system subjected to a set of design variables, inside a prescribed range of operation [37,38]. In the context of railway research, RSM has been used to maximise passenger comfort by optimising the stiffness of the suspension of a railway vehicle [39]. The same tool has been used to maximise the passive safety of railway passengers by optimising the geometry of seat structures $[40,41]$. The rail profile on a curved track section has also been optimised to minimise rail wear [42]. This paper proposes the use of RSM to support a systematic methodology for derailment assessment dealing with the uncertainty of vehicle and operation conditions.

This work assesses the impact of the vehicle conditions, such as asymmetric loading, defective suspension elements and speed, on the derailment potential of a freight wagon in realistic operation, using an RSM. A Design of Experiments (DoE) approach is used to cover different vehicle and operational scenarios. The vehicle and the track are modelled in the railway dynamics software VAMPIRE to obtain the wheel-rail contact forces. These interaction forces are filtered and processed to evaluate the maximum values of the derailment assessment quantities $Y / Q$ and $\Delta Q / Q_{0}$. An RSM is used to model the relation between the design variables and the derailment assessment quantities, and the vehicle conditions that maximise the derailment potential are identified using an optimisation procedure. 


\section{Case study}

The methodology proposed in this work is presented and demonstrated with a case study on the root causes of a train derailment that occurred in a railway line in Europe. Both the vehicle and track data are realistic, and the location of the Point of Derailment (POD) is estimated from the track damage. The hypothesis explored in this case study is that the causes for the derailment are related to the dynamic behaviour of the freight wagon and its compatibility with the track and operation conditions.

\subsection{Derailment scenario}

According to the information collected by the authors, the trailing wagon of a freight train derailed while negotiating a curve with a mean radius of $601 \mathrm{~m}$, a cant of $118.5 \mathrm{~mm}$, and a horizontal gradient, at an approximate speed of $100 \mathrm{~km} / \mathrm{h}(27.78 \mathrm{~m} / \mathrm{s})$. The train comprised over 10 Shimms wagons loaded with sheet metal coils. Figure 1 (a) presents a plan view of the track, represented by the parallel solid lines, and the trajectory of the derailed wagon represented by the parallel dashed lines, as inferred from the track damage and stopping position. The inner wheels of the wagon leapt the inner (left) rail on the curved section of the track, as depicted in Figure 1 (b). After the initiation of the derailment, the wagon travelled over the ballast and wooden sleepers for approximately $350 \mathrm{~m}$ before colliding with a rail crossing located next to the exit of the curve.

[Figure 1 here]

It must be stressed that only the trailing wagon of the complete train derailed, and all others remained on the track. The inspection of the wagon, after the derailment, shows that the Lenoir links in the high wheels of the rear wheelsets of the two bogies were missing. It is not 
clear if the failure of the Lenoir links happened before or after the derailment and to what extent it can be a contributing factor to the derailment.

The simulation of the running dynamics of a railway vehicle requires modelling the track geometry. At the time of the derailment, the track consisted of UIC $54 \mathrm{~kg} / \mathrm{m}$ rail profiles with $1 / 20$ inclination laid out in Iberian gauge of $1.668 \mathrm{~m}$. Figure 2 presents the horizontal track layout for the track section where the derailment occurred. The VAMPIRE model of the track requires the description of the track layout shown in a tabular form. Since the track irregularities before the derailment are not available, measurements taken after the track was repaired are used. These irregularities, shown in Figure 2, are consistent with the track layout and operation condition of the line, being a reliable representation of the condition of the track. The damage to the sleepers, caused by the wheels of the derailed wagon, starts at a track distance of approximately $460 \mathrm{~m}$, from the origin of the track in Figure 2. This location is the end of a widened track gauge section. This position is preceded by an acute inversion of lateral alignment, at a track distance of $440 \mathrm{~m}$, which also presents a track dip regarding the longitudinal level, as depicted in Figure 2.

[Figure 2 here]

\subsection{Description of the freight wagon}

The freight wagon involved in the derailment, shown in Figure 3, is used for the transportation of steel sheet coils and is classified as a Shimms type wagon. The wagon comprises a vehicle body supported by two Y21-Cse bogies. The vehicle body is a welded metal structure made of a rigid underframe, with two vertical walls on its extremities. The top geometry of the chassis includes five cradles where sheet metal coils are transported. Table 1 presents the relevant characteristics of the Shimms wagon for modelling and simulation purposes. 
The structure of the Shimms wagon is presented in Figure 3. The primary suspension (PS) connects the bogies to the axleboxes, transmits the loads between the bogie and the wheelsets, filters the vibrations, and dissipates energy through load-dependent friction dampers. The secondary suspension (SS) supports the vehicle body and transmits the vertical, longitudinal, and lateral loads to the bogie. The SS also generates the friction torque that resists the relative yaw rotation between the bogies and the vehicle body, to improve the lateral stability. The sheet metal coils are transported on top of the cradles inside the vehicle body.

[Table 1 here]

\section{[Figure 3 here]}

The Y21-Cse is a series of UIC standard bogies similar to the more common Y25 family, which is equipped with Lenoir-link suspensions that have a bi-linear vertical stiffness characteristic and load-dependent friction damping. The Y21 bogie is composed of a welded rigid frame with a bolster, two wheelsets, four axleboxes, the PS, and the braking systems. The vertical loads on the bogie frame are transferred to the axleboxes through vertical helicoidal springs, shown in Figure 4 (a). The stiffness of the suspension is adjusted to the varying load conditions using vertical tare springs combined with concentric vertical laden springs. The laden springs have a shorter undeformed length than the tare springs and only come into contact with the bogie frame when the vertical load exceeds a defined threshold. Each pair of springs, i.e. tare and laden springs in parallel, transfers $1 / 8$ of the load from the bogie frame to the axlebox. The outer tare springs connect the bogie frame directly to the axlebox, as shown in Figure 4 (a). The inner tare spring is compressed between the spring cap and the axlebox, while the inner laden spring connects the bogie frame directly to the axlebox. 
The load-dependent friction damping characteristics of the Y21 bogie are related to the Lenoir link: an inclined link that connects the spring cap to the bogie frame. The Lenoir link is subjected to a tension force $f_{\mathrm{L}}$ caused by the compressive force $f_{\mathrm{k}}$ on the inner tare spring, as depicted in Figure 4 (b). Force $f_{\mathrm{L}}$, in the line of action of the Lenoir link, can be decomposed in $f_{\mathrm{k}}$ and the horizontal force $f_{\mathrm{h}}$, transmitted by the spring cap to the pusher. $f_{\mathrm{h}}$ and $f_{\mathrm{k}}$ are related by:

$$
\frac{f_{\mathrm{h}}}{f_{\mathrm{k}}}=\operatorname{tg} \theta
$$

where $\theta$ is the inclination of the Lenoir link. Assuming very small variations in $\theta$, an increase in the vertical load $f_{\mathrm{k}}$ on the tare spring causes an increase in the contact force $f_{\mathrm{h}}$ transferred to the pusher. The spring cap transmits force $f_{\mathrm{h}}$ to the pusher, which, in turn, transfers this load to the axlebox in the form of a normal reaction force $f_{\mathrm{N}}$. The axleboxes and the guides in the bogie frame are lined with friction surfaces, as shown in Figure 5. Force $f_{\mathrm{N}}$, normal to inner friction surface of the axlebox, leads to the development of vertical and lateral friction forces $f_{\mu}$, that are responsible for part of the friction damping in the PS. It is clear that the damage or removal of the Lenoir link eliminates this source of damping of the primary suspension.

\section{[Figure 5 here]}

The axleboxes are constrained laterally and longitudinally by guides in the bogie rigid frame. The movement of the axlebox, with respect to the bogie frame in the lateral and longitudinal directions, is allowed within a clearance. This allows the reduction of the wheelset angles of attack and, consequently, provides better curve negotiation characteristics [43]. 
Friction damping occurs between the outer guide of the bogie frame and the outer friction surface of the axlebox as a reaction to force $f_{\mathrm{N}}$ transferred by the pusher to the axlebox.

The VAMPIRE model of the freight wagon follows the general multibody formulation. The vehicle body, bogie frames, wheelsets, axleboxes and steel coils are the elements that account for most of the inertia of the vehicle. Compared to the springs of the suspensions, these bodies present a very high stiffness and are assumed as rigid bodies in the model. Springs, guides lined with friction surfaces, pivots, bumpstops and links limit the relative movement of the bodies and are represented by force elements in the multibody model. In the VAMPIRE model of the vehicle, although the Lenoir link is not explicitly modelled by kinematic joints, the formulation of the elements provided by VAMPIRE allows a representation of the loaddependent friction damping characteristics of the bogie. The general data for the vehicle model is presented in Appendix A.

The derailed vehicle was the trailing wagon of the complete train. Preliminary dynamic analysis reveal that using more than two wagons to model the train does not prompt meaningful variations on the dynamics of the trailing wagon. Therefore, the model of the train used in this work comprises only two identical wagons connected by buffer and screw couplings, which account for the constraint to the yaw motion caused by the connections between the vehicles. The longitudinal dynamics are simplified by assuming there are no relevant impacts and clearances between the wagons. These simplifications allow the use of a simplified model of the couplings, described in Appendix A.

\section{Derailment assessment}

Railway derailments are defined by a loss of lateral guidance and/or vertical support of the wheel by the rail. Consequently, the analysis of derailments is based on the analysis of the wheel-rail contact forces. The study of the dynamic behaviour of railway vehicles, including derailment analysis, is commonly performed using numerical simulations. In this work, the 
vehicle-track interaction is simulated using the commercial software VAMPIRE and the outputs of the simulations are the wheel-rail contact forces $Y$ and $Q$.

\subsection{Flange climb derailment}

Wheel flange climb derailment occurs when a flanging wheel climbs on top of the rail, leading to the loss of lateral guidance. This derailment mechanism is associated with situations where the flanging wheel is subjected to a high lateral impulse force combined with a drop in the vertical force that supports the wheel. The ratio of lateral contact force $Y$ to vertical contact force $Q$ on a wheel, $Y / Q$, represents the potential for flange climb derailment.

Several flange climb derailment criteria have been developed to study the likelihood of derailment occurring when there is contact between the flange and the rail. Most commonly, these criteria assume derailment occurs when the $Y / Q$ ratio exceeds a certain limit. Nadal proposes the first structured effort to explain flange climb derailment [44]. Nadal explains the derailment phenomenon using a 2D representation of the ratio of lateral force $Y$ and vertical force $Q$ at the flange contact point, assuming the flanging wheel is in a two-point contact condition, with the flange contact point leading, as shown in Figure 6. Based on the relation between the contact forces, Nadal defines the limiting value of $Y / Q$ above which derailment is likely to occur as:

$$
\frac{Y}{Q}=\frac{\tan \delta-\mu_{w, r}}{1+\mu_{w, r} \tan \delta}
$$

where $\delta$ is the angle of the plane of contact measured relative to the horizontal plane.

[Figure 6 here]

Despite more recent developments in the study of flange climb derailment, the singlewheel $Y / Q$ limit by Nadal is still widely used in academia and the industry as a first approximation to assess derailment safety. However, standards UIC 518 and EN 14363, define the single wheel 
$Y / Q$ limit in the case of on-track tests as 0.8 , which is a conservative figure compared to the value computed using the Nadal criterion.

\subsection{Loss of vertical support}

The loss of vertical support of the wheel raises the potential for derailment because the wheel is more vulnerable to sudden increases in the lateral force caused by discrete track irregularities, such as rail joints, switches and crossings. The reduction of the vertical wheel load may be induced by several factors: changes in track cant or track twist; cyclic track irregularities that excite the natural modes of vibration of the vehicle, such as roll, pitch, and bounce motions of the vehicle body $[35,45]$; asymmetric vehicle loading; and, defective suspension elements. The indicator used to characterise this derailment mechanism is the vertical wheel unloading:

$$
\frac{\Delta Q}{Q_{0}}=\frac{Q_{0}-Q}{Q_{0}}
$$

which is defined as the ratio between the variation of the vertical wheel load $\Delta Q$ and the static wheel load $Q_{0}$. Standards UIC 518 and EN 14363 do not provide a limit value of $\Delta Q / Q_{0}$ for the wheels in the case of dynamic running.

\subsection{Post-processing of simulation results}

In this work, the simulations of the wagon model are developed using the vehicle and track models described in the previous section, to obtain the wheel-rail forces $Y$ and $Q$ as a function of the track distance. Standard EN 14363 requires forces $Y$ and $Q$ to be filtered using a lowpass filter with a cut-off frequency of $20 \mathrm{~Hz}$ for the testing and approval of railway vehicles. Subsequently, the values of $Y / Q$ and $\Delta Q / Q_{0}$ are calculated using the filtered $Y$ and $Q$ data sets and filtered using a sliding window of $2 \mathrm{~m}$. The $99.85 \%$ percentile of the derailment assessment quantities in the full curved section is calculated to obtain the statistical maximum values [35]. 


\section{Response Surface Methodology}

The Response Surface Methodology (RSM) is a group of techniques used to develop reduced models of processes or systems. In the context of the present work, the RSM is used to generate response surfaces, also known as meta-models or surrogate models, that approximate the dynamic response of the vehicle as a function of selected parameters. The methodology involves the definition of a set of dynamic simulations, using a Design of Experiments methodology (DoE), that provide the values for the parameters on which derailment depends. This means that the DoE allows defining a set of modelling scenarios necessary to build the response surfaces. Afterwards, polynomial regression determines the response surface functions that establish the relationship between the vehicle modelling parameters and operational conditions, with the relevant output $Y / Q$ and $\Delta Q / Q_{0}$.

\subsection{Selection of design variables}

The derailment potential of the wagon can be interpreted as a function of several variables, of which some are more relevant than others, as their effect is dominant on the behaviour of the vehicle. The selected design variables used in this work are the lateral deviation of the position of the cargo relative to the longitudinal axis of the body of the rear vehicle, $t_{1}$, the braking moment applied to the wheelsets of both vehicles, $t_{2}$, the vehicle speed, $t_{3}$, and the condition of the Lenoir links in the primary suspensions of the bogies of the rear vehicle, $t_{4}$, as listed in Table 2. It is reasonable to consider the lateral deviation of the cargo due to potential human errors or the defective securing on the placement of the coils on the vehicle. In VAMPIRE, this is modelled by offsetting the centre of gravity of the coils in the lateral direction. A braking moment is allowed to vary between zero, i.e., when the train negotiates the curve at constant speed, and a high braking moment of $8 \mathrm{kN} . \mathrm{m}$ representative of an emergency braking scenario. In VAMPIRE, this braking moment is applied individually on the pitch axis of each wheelset. 
It is also known that the speed at which the train operates in the track section considered is approximately $100 \mathrm{~km} / \mathrm{h}$. Consequently, the range considered for the operation speed is between $90 \mathrm{~km} / \mathrm{h}$, and $110 \mathrm{~km} / \mathrm{h}$, which is the speed limit on this track section. Three distinct conditions of the Lenoir links are considered: perfect conditions; failure of the Lenoir link in the high wheel of the rear wheelset of the leading bogie; and, failure of the Lenoir link of the rear wheelset of the trailing bogie. Note that the Lenoir link failure condition requires modifications to the VAMPIRE models of the rear vehicle. The compression forces and installed lengths of the springs in the bogies are determined to guarantee the correct redistribution of the vertical loads in the springs in the new equilibrium condition. The static and dynamic loads associated with the extended inner tare spring, on the outer bumpstop and on the friction surfaces, are removed. The redistribution of vertical loads also changes the static normal loads in the other bumpstops and friction surfaces of the PS.

[Table 2]

\subsection{Design of Experiments}

A Design of Experiments (DoE) approach is used to define the combinations of the design variables, used in the computer experiments. This approach allows minimising the number of experiments required to obtain an acceptable representation of the behaviour of a system. The choice of the design depends on the purpose of the analysis. In this work, the computer experiments are the simulations providing $Y / Q$ and $\Delta Q / Q_{0}$. According to the Response Surface Methodology, the relationship between the derailment assessment quantities and the associated vehicle and operational conditions is established using polynomial regression. In most applications, a second-order polynomial model provides an acceptable approximation of the behaviour of the system in a limited range of conditions of operation [38]. This work uses the 
Central Composite Design (CCD), which is one of the most common approaches used to build second-order models [37]. The CCD is a $2^{k}$ factorial design with one central run and $2 k$ axial runs, where $k$ is the number of design variables. Thus, the number of experiments i.e. computer simulations, required is:

$$
n=1+2 k+2^{k}
$$

The design variables are scaled and made dimensionless for the computer experiments. The range of the design variables is defined by $t_{i}^{\min } \leq t_{i} \leq t_{i}^{\max }$. The value $t_{\mathrm{i}}$ of the design variables can be related to the value of the coded design variables $x_{i}$ through:

$$
t_{i}=t_{i}^{0}+x_{i} s_{i} \quad i=1, \ldots, k
$$

where the slope $s_{i}$ is determined for each variable according to:

$$
s_{i}=\frac{t_{i}^{\max }-t_{i}^{0}}{x_{i}^{\max }} \quad i=1, \ldots, k
$$

The design variables, $t_{1}, t_{2}$ and $t_{3}$ are continuous and are used in the CCD, whereas the variable that defines the Lenoir link state, $t_{4}$, is a categorical variable. This fact requires the generation of a response surface for each of the three Lenoir link conditions considered. Therefore, the number of continuous variables is $k=3$, which results in $n=15$ computer experiments for each of the Lenoir link conditions. The CCD defines the values of the design variables that must be used in the vehicle and operation scenarios according to the coded variable values shown in Figure 7. Considering $k=3$, there is one central point in the intersection of the axes, six axial runs positioned on the axes at a coordinate defined by the rotatability parameter $\alpha=\left[2^{k}\right]^{1 / 4}$, and eight factorial runs that define the vertices of the cube. The conversion between the coded variables and the real values of the design variables is determined using Equations (5) and (6) and the results are presented in Table 3. 
[Table 3 here]

The values of the coded variables for each run are represented by matrix $\mathbf{D}$, where the columns are associated with one of the design variables, and the rows with the runs. For $k=3$, matrix $\mathbf{D}$ of the coded design parameters is given by [37]:

$$
\mathbf{D}=\left[\begin{array}{ccccccccccccccc}
-1 & 1 & -1 & 1 & -1 & 1 & -1 & 1 & -\alpha & \alpha & 0 & 0 & 0 & 0 & 0 \\
-1 & -1 & 1 & 1 & -1 & -1 & 1 & 1 & 0 & 0 & -\alpha & \alpha & 0 & 0 & 0 \\
-1 & -1 & -1 & -1 & 1 & 1 & 1 & 1 & 0 & 0 & 0 & 0 & -\alpha & \alpha & 0
\end{array}\right]^{T}
$$

where $\alpha=1.682$. Therefore, the total number of simulations required for the analysis is $3 \times 15$ $=45$. Table 4 lists the values of the design variables used in the complete set of 45 simulations. The simulations are identified with an ID. The ID values 01 to 15 refer to the failure of the Lenoir link on wheel W2R, of 16 to 30 refer to the vehicle with the suspension in perfect conditions, and the number in the range of 31 to 45 are associated with the failure of the Lenoir link on wheel W4R.

[Table 4 here]

\subsection{Polynomial regression}

The response surface is a mathematical representation of the response of a system subjected to a set of design variables. The second-order response surface model function used to approximate the behaviour of a system in a prescribed range of the $k$ input variables $\boldsymbol{x}$ is [37]:

$$
y(x)=\beta_{0}+\sum_{j=1}^{k} \beta_{j} x_{j}+\sum_{j=1}^{k} \beta_{j j} x_{j}^{2}+\sum_{i<j} \sum \beta_{i j} x_{i} x_{j}
$$


where $y(\boldsymbol{x})$ is the response surface function, $\beta_{0}, \beta_{j}$ and $\beta_{i j}$ are the coefficients of the polynomial, and $x_{i}$ and $x_{j}$ are the coded variables. In the case of $k=3$, the response surface function is:

$y\left(x_{1}, x_{2}, x_{3}\right)=\beta_{0}+\beta_{1} x_{1}+\beta_{2} x_{2}+\beta_{3} x_{3}+\beta_{11} x_{1}^{2}+\beta_{22} x_{2}^{2}+\beta_{33} x_{3}^{2}+\beta_{12} x_{1} x_{2}+\beta_{13} x_{1} x_{3}+\beta_{23} x_{2} x_{3}$

resulting in a set of ten unknown coefficients $\boldsymbol{\beta}=\left[\begin{array}{llllllllll}\beta_{0} & \beta_{1} & \beta_{2} & \beta_{3} & \beta_{11} & \beta_{22} & \beta_{33} & \beta_{12} & \beta_{13} & \beta_{23}\end{array}\right]^{T}$ of the polynomial. The problem of generating a response surface consists in the determination of the vector $\boldsymbol{\beta}$ that delivers the best fit between the data obtained through the numerical simulations and the response surface function $y(\boldsymbol{x})$. This is achieved by solving the linear system of equations:

$$
\boldsymbol{\beta}=\left(\boldsymbol{X}^{T} \boldsymbol{X}\right)^{-1} \boldsymbol{X}^{T} \hat{y}
$$

for the coefficients $\boldsymbol{\beta}$, where $\hat{y}$ is the vector of the simulated response quantities and $\boldsymbol{X}$ is a matrix defined as:

$$
\boldsymbol{X}=\left[\begin{array}{cccccccccc}
1 & D_{11} & D_{12} & D_{13} & D_{11}^{2} & D_{12}^{2} & D_{13}^{2} & D_{11} D_{12} & D_{11} D_{13} & D_{12} D_{13} \\
: & : & : & : & : & : & : & : & : & : \\
1 & D_{n 1} & D_{n 2} & D_{n 3} & D_{n 1}^{2} & D_{n 2}^{2} & D_{n 3}^{2} & D_{n 1} D_{n 1} & D_{n 1} D_{n 3} & D_{n 2} D_{n 3}
\end{array}\right]
$$

in which $D_{\mathrm{ij}}$ refer to the coefficients of matrix $\mathbf{D}$ given by Equation (7). The response surfaces are generated individually for $Y / Q$ and $\Delta Q / Q_{0}$ on each wheel of the derailed vehicle. The simulated response $\hat{y}$ is a vector with the post-processed results of $Y / Q$ and $\Delta Q / Q_{0}$ for each set of 15 simulations with the models defined with the parameters listen in Table 4.

\section{Identification of unsafe conditions potentially leading to derailment}

This work aims to assess and identify which combination of vehicle and operational conditions may expose the vehicle to unsafe running, and eventually derailment, using a response surface methodology. In this section, the wheels of the derailed wagon are identified by letter W, followed by a number that specifies the wheelset, and a capital letter that defines the side. Wheelsets are numbered 1 to 4 from the front to the rear of the vehicle. Capital letter R refers 
to the outer side of the curve, while letter L refers to the inner side. For example, wheel W2R is the outer wheel of the trailing wheelset of the front bogie. All the results presented hereafter refer to the derailed wagon, i.e., the trailing vehicle.

Figure 8 presents the complete set of maximum values of the post-processed quantity $Y / Q$ obtained from the dynamic simulations of the 45 scenarios. The high wheels, i.e., the wheels on the outer side of the curve, present the larger values of $Y / Q$, due to the natural tendency for flange contact between the wheels and the rails. The large values are prominent in the high wheels of the leading wheelsets of both the front and rear bogies, i.e., wheels W1R and W3R. Figure 9 presents the track irregularities and the results of $Y / Q$ on wheels W1R and W3R in scenario 20. The $\mathrm{x}$-axes of the plots are limited to the vicinity of the position where the highest value of $Y / Q$ is registered, approximately $460 \mathrm{~m}$. This kilometric point is close to the position where the track damage due to the derailment starts. The maximum value of $Y / Q$ occurs in a track position defined by a vertical dip, combined with an inversion of sign in the lateral alignment, and a reduction in track gauge. This increase in $Y / Q$ is consistent with the combination of lateral and gauge track irregularities, that promotes an increase in the angle of attack between the leading wheelsets and the outer rail. Regardless of the wheel, the $Y / Q$ value does not exceed the limit of 0.8 defined in standard EN 14363, suggesting flange climb is not the single derailment mechanism associated with this case study.

[Figure 8 here]

[Figure 9 here]

Figure 10 shows the maximum values of the post-processed $\Delta Q / Q_{0}$ results from the simulation batch. The higher values of $\Delta Q / Q_{0}$ are found on the inner wheels, while the outer 
wheels exhibit lower values. This is explained by the non-compensated lateral acceleration of the vehicle in the curved section of the track. The vehicle traverses the curve at a higher speed than the equilibrium speed, which explains the transfer of static wheel load from the inner to the outer wheels. Figure 11 shows the results of $\Delta Q / Q_{0}$ on the inner wheels in scenario 14, which presents the highest value of $\Delta Q / Q_{0}$ from the 45 scenarios. The wheel W3L presents the highest wheel unloading, while wheel W4L, on a trailing wheelset, presents a value of $\Delta Q / Q_{0}$ comparable to that of wheel W1L, on the leading wheelset of the front bogie. This demonstrates there is a higher tendency for wheel unloading on the rear bogie.

[Figure 10 here]

[Figure 11 here]

Following this preliminary analysis, the study of the derailment focuses on the conditions that maximise $Y / Q$ on the leading outer wheels of the vehicle, i.e., positions $\mathrm{W} 1 \mathrm{R}$ and W3R, and the conditions that maximise wheel unloading $\Delta Q / Q_{0}$ on the lower wheels of the rear vehicle, i.e., positions $\mathrm{W} 1 \mathrm{~L}, \mathrm{~W} 2 \mathrm{~L}, \mathrm{~W} 3 \mathrm{~L}$, and W4L. The investigation of the response surfaces provides more insight into the combined effect of the design variables on the derailment process. The combinations of design variables that lead to the maximum values of the response surfaces of $Y / Q$ and $\Delta Q / Q_{0}$ on the selected wheels are obtained with an optimisation procedure. The surface responses are first generated using the results of the experiments, shown in Figure 8 and Figure 10, to build the $\hat{y}$ vector in Equation (10) and applying the procedure presented in Section 4. For each response surface, a stepwise regression method is used to determine which of the regression coefficients are statistically significant, i.e., unlikely to be zero in the regression model [37]. For each response surface function, the 
conditions that maximise $Y / Q$ and $\Delta Q / Q_{0}$ are identified using the optimisation method known as the interior point. The maximum values of $Y / Q$ and $\Delta Q / Q_{0}$ on the selected wheels, and the corresponding parameters, i.e., the sets of vehicle and operational conditions, are presented in Table 5.

In all cases, the maximum values of $Y / Q$ on the outer wheels are associated with the lateral deviation of the cargo to the inner side of the curve, that causes a reduction of the vertical wheel load on the outer wheels. The maximum value of $Y / Q$ is 0.744 on wheel $\mathrm{W} 3 \mathrm{R}$, which is lower than the limit of 0.8 defined on standard EN 14363. The lateral deviation of the cargo causes a roll torque on the vehicle body, inducing asymmetric wheel static loads. Consequently, positive values of the lateral deviation of the cargo, i.e., lateral deviations to the outer side of the curve, increase the wheel unloading $\Delta Q / Q_{0}$ on the inner wheels. The maximum predicted value of $\Delta Q / Q_{0}$ is 0.773 on position W3L. It is also worth noting that the maximum values of $\Delta Q / Q_{0}$ are consistently higher on the inner wheels of the rear bogie. The effect of the braking moment is not clear from the inspection of Table 5. The speed of the train is related to the lateral acceleration responsible for the distribution of quasi-static vertical wheel force when the vehicle negotiates the curve. The increase in speed generally aggravates the maximum values of the derailment assessment quantities. A simultaneous increase of the lateral wheel forces on the outer wheels and the increase of the vertical wheel load on the outer wheels at the expense of the reduction of wheel load on the inner wheels is consistently observed. The fact that the vehicle derailed to the inner side of the curve suggests that the maximum $Y / Q$ values determined on the outer wheels cannot be associated with the cause of the derailment. On the other hand, the analysis suggests the inner wheel of the leading wheelset of the rear bogie, i.e., position W3L presents the highest derailment potential of all wheels of the wagon, due to excessive vertical unloading. 
The test on the statistical significance of the design variables reveals that regressor $t_{2}$, i.e., the braking moment, is not significant at the 0.05 level except for the response surface of $\Delta Q / Q_{0}$ on wheel W2L in the case of a failure of the Lenoir link on wheel W2R. This means that the value of the braking moment does not contribute to explain the behaviour of most response surfaces.

[Table 5 here]

The impact of the different design variables on $\Delta Q / Q_{0}$ of wheel W3L can be further investigated by examining the plots of the response surface functions. Figure 12 shows the response surfaces for the three Lenoir link conditions considered, as a function of the lateral deviation of the coil and the vehicle speed. The response surfaces and the regressors of the design variables, $t_{1}$, the lateral deviation of the cargo, and $t_{3}$, the operation speed, for the three conditions of the Lenoir links, are statistically significant at the 0.05 level as shown in Tables 6-8. The maximum values of $\Delta Q / Q_{0}$, identified by dots in the plots, confirm that the increase of speed and lateral deviation of the coils to the outer side of the curve are aggravating factors for the derailment potential of wheel W3L, with respect to wheel unloading. The combination of conditions that maximises the derailment potential of the wheel $\mathrm{W} 3 \mathrm{~L}$ is presented on the central surface of Figure 12. The lateral deviation of the coils $0.08 \mathrm{~m}$ to the outer side of the curve, the vehicle speed of $110 \mathrm{~km} / \mathrm{h}$, and failure of the Lenoir link in the position W2R constitute the most favourable set of conditions for derailment. Notably, the response surfaces suggest that the failure of a Lenoir link on the front bogie has an important impact on the unloading of a wheel of the rear bogie.

[Figure 12] 
[Table 6 here]

[Table 7 here]

[Table 8 here]

The accuracy of the predictions obtained from the response surfaces can be compared against the results obtained with VAMPIRE simulations for the same conditions, presented in Table 9. Contrary to the previous analysis of the response surfaces, the maximum wheel unloading is associated with the failure of the Lenoir link in the position W4R, that is, in the rear bogie. This is in agreement with the expected behaviour, because the failure of a Lenoir link causes the redistribution of the static wheel loads on the bogie, as explained in Figure 13. The vertical wheel load on a defective wheel is reduced, and a static force balance requires the diagonally opposite wheels to unload and the remaining wheels to load. In the context of the rear bogie, the failure of the Lenoir link on the wheel W4R leads to a decrease of static force on wheel W3L, causing the increase in wheel unload $\Delta Q / Q_{0}$ that contributes to maximise the derailment potential of the wagon.

Nonetheless, Table 9 shows a satisfactory agreement between the results for the most adverse scenarios using VAMPIRE and RSM, demonstrating the convenience and effectiveness of the Response Surface Methodology to support the identification of the most favourable scenarios for the derailment, when its circumstances are uncertain. The discrepancy on the identification of the Lenoir link failure that maximises the derailment potential can be attributed to the simplifications and assumptions used for modelling the suspension of the bogie. This is 
particularly relevant when simulating such adverse scenarios as the derailment of a freight wagon.

[Table 9 here]

[Figure 13]

\section{Conclusions}

This work presents a study of railway dynamics using multibody simulations to analyse the impact of vehicle and operational conditions on the derailment potential of a freight wagon running on a railway track. A response surface methodology supports the investigation of the combined effects of asymmetric loading, braking moments, vehicle speed and suspension conditions on the derailment dynamics. The conditions that maximise the derailment assessment quantities $Y / Q$ and $\Delta Q / Q_{0}$ on each wheel are predicted with an optimisation procedure applied to the response surfaces. The results of the response surfaces are compared with dynamic simulations run in VAMPIRE for the detailed model under the same worst-case conditions, demonstrating a similar precision of the vehicle dynamic response.

The response surfaces consistently predict $Y / Q$ values on the outer wheels under the limit defined in standard EN 14363, thus suggesting that flange climb is not the single derailment mechanism associated with this derailment. However, the inner wheels of the rear bogie of the rear vehicle present extreme values of wheel unloading $\Delta Q / Q_{0}$. These results support the idea that despite the assessment quantities not exceeding the safety limits, a derailment can still occur. The most adverse scenario, that maximises wheel unloading $\Delta Q / Q_{0}$ on the inner wheel of the leading wheelset of the rear bogie, corresponds to a combination of the lateral deviation of the cargo to the outer side of the curve, excessive speed, and failure of 
a Lenoir link. The response surface methodology provides an efficient evaluation of the derailment potential in the presence of uncertain vehicle and operation conditions. Furthermore, this methodology offers a framework to define the limits of safe operation of railway vehicles.

The results presented in this work can be further improved using more sophisticated models of the suspension of the wagons, to represent the interaction between the components more precisely. This includes the explicit modelling of the Lenoir link and the pusher to couple the vertical and longitudinal stiffnesses of the suspension, rather than the modelling force relationships available in VAMPIRE. Also, the effect of the longitudinal dynamics can be investigated in further detail to understand how the inter-vehicle forces that develop under braking may contribute to wheel unloading. In the context of this work, this requires more advanced modelling of the buffers and coupler. A more detailed model of the vehicles and couplings is expected to improve the accuracy of simulations of the vehicle behaviour in limit conditions, such as derailments.

\section{Acknowledgements}

The Portuguese Foundation for Science and Technology (Fundação para a Ciência e a Tecnologia) grant PD/BD/128138/2016 is gratefully acknowledged. This work was supported by the Portuguese Foundation for Science and Technology, through IDMEC, under LAETA, project UIDB/50022/2020.

\section{References}

[1] Iwnicki S. Handbook of Railway Vehicle Dynamics. Boca Raton: CRC Press; 2006.

[2] Magalhães H, Ambrósio J, Pombo J. Railway vehicle modelling for the vehicle-track interaction compatibility analysis. Proc. Inst. Mech. Eng. Part K J. Multi-body Dyn. 2016;230:251-267. 
[3] $\mathrm{Wu} \mathrm{H}$, Robeda J. Effects of bogie centre plate lubrication on vehicle curving and lateral stability. Veh. Syst. Dyn. 2004;41:292-301.

[4] Iwnicki SD, Stichel S, Orlova A, et al. Dynamics of railway freight vehicles. Veh. Syst. Dyn. 2015;53:995-1033.

[5] Stichel S. Limit cycle behaviour and chaotic motions of two-axle freight wagons with friction damping. Multibody Syst. Dyn. 2002;8:243-255.

[6] Evans J, Rogers PJ. Validation of dynamic simulations of rail vehicles with friction damped Y25 bogies. Veh. Syst. Dyn. 1998;29:219-233.

[7] Bosso N, Gugliotta A, Soma` A. Multibody Simulation of a Freight Bogie With Friction Dampers. Jt. Rail. ASMEDC; 2002. p. 47-56.

[8] Molatefi H, Hecht M, Kadivar MH. Critical speed and limit cycles in the empty Y25-freight wagon. Proc. Inst. Mech. Eng. Part F J. Rail Rapid Transit. 2006;220:347-359.

[9] Karis T, Berg M, Stichel S, et al. Correlation of track irregularities and vehicle responses based on measured data. Veh. Syst. Dyn. 2018;56:967-981.

[10] Recuero AM, Escalona JL. Dynamics of the coupled railway vehicle-flexible track system with irregularities using a multibody approach with moving modes. Veh. Syst. Dyn. 2014;52:45-67.

[11] Suarez B, Felez J, Antonio Lozano J, et al. Influence of the track quality and of the properties of the wheel-rail rolling contact on vehicle dynamics. Veh. Syst. Dyn. 2013;51:301-320.

[12] Magalhães H, Pombo J, Ambrósio J, et al. Rail vehicle design optimization for operation in a mountainous railway track. Innov. Infrastruct. Solut. 2017;2:31.

[13] Weidemann C. State-of-the-Art Railway Vehicle Design with Multi-Body Simulation. J. Mech. Syst. Transp. Logist. 2010;3:12-26.

[14] Bruni S, Meijaard JP, Rill G, et al. State-of-the-art and challenges of railway and road 
vehicle dynamics with multibody dynamics approaches. Multibody Syst. Dyn. 2020.

[15] Wilson N, Fries R, Witte M, et al. Assessment of safety against derailment using simulations and vehicle acceptance tests: A worldwide comparison of state-of-the-art assessment methods. Veh. Syst. Dyn. 2011;49:1113-1157.

[16] Brabie D, Andersson E. Dynamic simulation of derailments and its consequences. Veh. Syst. Dyn. 2006;44:652-662.

[17] Clementson J, Evans J. The Use of Dynamic Simulation in the Investigation of Derailment Incidents. Veh. Syst. Dyn. 2016;37:338-349.

[18] Di Gialleonardo E, Premoli A, Gallazzi S, et al. Sloshing effects and running safety in railway freight vehicles. Veh. Syst. Dyn. 2013;51:1640-1654.

[19] Polach O, Böttcher A, Vannucci D, et al. Validation of simulation models in the context of railway vehicle acceptance. Proc. Inst. Mech. Eng. Part F J. Rail Rapid Transit. 2015;229:729-754.

[20] Pombo J. Application of a Computational Tool to Study the Influence of Worn Wheels on Railway Vehicle Dynamics. J. Softw. Eng. Appl. 2012;05:51-61.

[21] Facchinetti A, Mazzola L, Alfi S, et al. Mathematical modelling of the secondary airspring suspension in railway vehicles and its effect on safety and ride comfort. Veh. Syst. Dyn. 2010;48:429-449.

[22] Suarez B, Mera JM, Martinez ML, et al. Assessment of the influence of the elastic properties of rail vehicle suspensions on safety, ride quality and track fatigue. Veh. Syst. Dyn. 2013;51:280-300.

[23] Escalona JL, Aceituno JF, Urda P, et al. Railway multibody simulation with the knifeedge-equivalent wheel-rail constraint equations. Multibody Syst. Dyn. 2020;48:373-402.

[24] Magalhães H, Marques F, Liu B, et al. Implementation of a non-Hertzian contact model for railway dynamic application. Multibody Syst. Dyn. 2020;48:41-78. 
[25] Marques F, Magalhães H, Pombo J, et al. A three-dimensional approach for contact detection between realistic wheel and rail surfaces for improved railway dynamic analysis. Mech. Mach. Theory. 2020;149:103825.

[26] Marques F, Magalhães H, Liu B, et al. On the generation of enhanced lookup tables for wheel-rail contact models. Wear. 2019;434-435:202993.

[27] Conti R, Meli E, Ridolfi A. A full-scale roller-rig for railway vehicles: multibody modelling and Hardware In the Loop architecture. Multibody Syst. Dyn. 2016;37:69-93.

[28] Ambrósio J, Pombo J. A unified formulation for mechanical joints with and without clearances/bushings and/or stops in the framework of multibody systems. Multibody Syst. Dyn. 2018;42:317-345.

[29] Pombo J, Ambrósio J, Silva M. A new wheel-rail contact model for railway dynamics. Veh. Syst. Dyn. 2007;45:165-189.

[30] Antunes P, Magalhães H, Ambrósio J, et al. A co-simulation approach to the wheel-rail contact with flexible railway track. Multibody Syst. Dyn. 2019;45:245-272.

[31] Rahmati-Alaei A, Sharavi M, Samadian Zakaria M. Hunting stability analysis of partially filled tank wagon on curved track using coupled CFD-MBD method. Multibody Syst. Dyn. 2019;

[32] Koo JS, Cho HJ. A method to predict the derailment of rolling stock due to collision using a theoretical wheelset derailment model. Multibody Syst. Dyn. 2012;27:403-422.

[33] Sunami H, Morimura T, Terumichi Y, et al. Model for analysis of bogie frame motion under derailment conditions based on full-scale running tests. Multibody Syst. Dyn. $2012 ; 27: 321-349$.

[34] Xiao X, Jin X, Wen Z, et al. Effect of tangent track buckle on vehicle derailment. Multibody Syst. Dyn. 2011;25:1-41.

[35] EN 14363:2016+A1:2018 Railway applications - Testing and Simulation for the 
acceptance of running characteristics of railway vehicles - Running Behaviour and stationary tests. European Committee for Standardization (CEN), Brussels; 2018.

[36] UIC 518 Testing and approval of railway vehicles from the point of view of their dynamic behaviour - Safety - Track fatigue - Running behaviour. International Union of Railways (UIC), Paris; 2009.

[37] Montgomery D. Design and Analysis of Experiments. 8th ed. New Jersey: John Wiley \& Sons, Inc.; 2013.

[38] Myers R, Montgomery D, Anderson-Cook C. Response Surface Methodology: Process and Product Optimization Using Designed Experiments. 4th ed. New Jersey: John Wiley \& Sons, Inc.; 2016.

[39] Martowicz A, Kurowski P, Uhl T, et al. Design Optimization of Multibody Model of Rail Vehicle Supported by Response Surface Method. Proc. 2nd Int. Conf. Eng. Optim. Lisbon; 2010.

[40] Carvalho M, Milho J, Ambrosio J, et al. Railway occupant passive safety improvement by optimal design. Int. J. Crashworthiness. 2017;22:624-634.

[41] Carvalho MS, Martins AP, Milho J. Railway seat design for injury mitigation in crash scenario. Int. J. Rail Transp. 2019;1-19.

[42] Wang J, Chen S, Li X, et al. Optimal rail profile design for a curved segment of a heavy haul railway using a response surface approach. Proc. Inst. Mech. Eng. Part F J. Rail Rapid Transit. 2016;230:1496-1508.

[43] EN 16235:2013 Railway application - Testing for the acceptance of running characteristics of railway vehicles - Freight wagons - Conditions for dispensation of freight wagons with defined characteristics from on-track tests according to EN 14363. European Committee for Standardization (CEN), Brussels; 2013.

[44] Nadal J. Locomotives à Vapeur. Collect. Encycl. Sci. Bibliotéque Mécanique Appliquée 
Génie. Paris, France; 1908.

[45] Zhang Z, Dhanasekar M. Dynamics of railway wagons subjected to braking torques on defective tracks. Veh. Syst. Dyn. 2012;50:109-131. 


\section{Appendix A - VAMPIRE model of the vehicle}

The VAMPIRE Transient simulations are run using the non-linear wheel rail contact. The VAMPIRE default values of track stiffness and damping are used. The wheel profile used is a simplified S1002 profile, with a radius of $460 \mathrm{~mm}$.

Table A.1 - Vehicle body: mass and inertia properties and initial positions of the CM of the rigid bodies.

\begin{tabular}{|c|c|c|c|c|c|c|c|c|}
\hline \multirow{2}{*}{ ID } & \multirow{2}{*}{ Body } & \multirow{2}{*}{$\begin{array}{c}\text { Mass } \\
{[\mathrm{kg}]}\end{array}$} & \multicolumn{3}{|c|}{ Inertia properties $\left[\mathrm{kg} \cdot \mathrm{m}^{2}\right]$} & \multicolumn{3}{|c|}{ Initial position $[\mathrm{m}]$} \\
\cline { 4 - 10 } & & $I_{\text {roll }}$ & $I_{\text {pitch }}$ & $I_{\text {yaw }}$ & $X_{0}$ & $Y_{0}$ & $H_{0}$ \\
\hline 101 & Vehicle body & 14100 & 15900 & 204500 & 207300 & 0 & 0 & 1.541 \\
\hline 102 & Front Coil & 23880 & 10200 & 11200 & 10200 & 3.9 & 0 & 2.191 \\
\hline 103 & Rear Coil & 23880 & 10200 & 11200 & 10200 & -3.9 & 0 & 2.191 \\
\hline
\end{tabular}

Note: the coils are rigidly connected to the vehicle body. 
Table A.2 - Y21 front bogie: mass and inertia properties and initial positions of the CM of the rigid bodies

\begin{tabular}{|c|c|c|c|c|c|c|c|c|}
\hline \multirow{2}{*}{ ID } & \multirow{2}{*}{ Body } & \multirow{2}{*}{$\begin{array}{c}\text { Mass } \\
{[\mathrm{kg}]}\end{array}$} & \multicolumn{2}{|c|}{ Inertia properties $\left[\mathrm{kg} . \mathrm{m}^{2}\right]$} & \multicolumn{4}{|c|}{ Initial position [m] } \\
\cline { 5 - 10 } & & & $I_{\text {roll }}$ & $I_{\text {pitch }}$ & $I_{\text {yaw }}$ & $X_{0}$ & $Y_{0}$ & $H_{0}$ \\
\hline 201 & Bogie Frame & 1900 & 1200 & 1500 & 2600 & 3.5 & 0 & 0.586 \\
\hline 202 & Wheelset Front & 1440 & 1130 & - & 1130 & 4.5 & 0 & 0.460 \\
\hline 203 & Wheelset Rear & 1440 & 1130 & - & 1130 & 2.5 & 0 & 0.460 \\
\hline 204 & Side Bearer Right & 10 & 10 & 10 & 10 & 3.5 & 0.85 & 0.896 \\
\hline 205 & Side Bearer Left & 10 & 10 & 10 & 10 & 3.5 & -0.85 & 0.896 \\
\hline
\end{tabular}


Table A.3 - Y21 front bogie: shear spring elements of the PS.

\begin{tabular}{|c|c|c|c|c|c|c|c|c|c|c|c|c|}
\hline \multirow{3}{*}{$\begin{array}{c}\text { ID } \\
1 \\
\end{array}$} & \multicolumn{2}{|c|}{ Bodies } & \multirow{2}{*}{\multicolumn{3}{|c|}{$\begin{array}{c}\text { Stiffness }\left(k_{\mathrm{X}} / k_{\mathrm{Y}} / k_{\mathrm{Z}}\right) \\
{[\mathrm{kN} / \mathrm{m}]}\end{array}$}} & \multirow{3}{*}{$\begin{array}{c}\begin{array}{c}\text { Undef. length } l_{0} \\
{[\mathrm{~m}]}\end{array} \\
0.234\end{array}$} & \multirow{2}{*}{\multicolumn{3}{|c|}{$\begin{array}{c}\mathrm{P}_{i}\left(X_{0} / Y_{0} / H_{0}\right) \\
{[\mathrm{m}]}\end{array}$}} & \multirow{2}{*}{\multicolumn{3}{|c|}{$\begin{array}{c}\mathrm{P}_{j}\left(X_{0} / Y_{0} / H_{0}\right) \\
{[\mathrm{m}]}\end{array}$}} \\
\hline & \multirow{2}{*}{$\begin{array}{c}i \\
201 \\
\end{array}$} & \multirow{2}{*}{$\frac{j}{202}$} & & & & & & & & & & \\
\hline & & & 555 & 555 & 968 & & 4.815 & 1.085 & 0.544 & 4.815 & 1.085 & 0.326 \\
\hline 2 & 201 & 202 & 469 & 469 & 595 & 0.260 & 4.815 & 1.085 & 0.544 & 4.815 & 1.085 & 0.326 \\
\hline 3 & 201 & 202 & 555 & 555 & 968 & 0.234 & 4.185 & 1.085 & 0.544 & 4.185 & 1.085 & 0.544 \\
\hline 4 & 201 & 202 & 469 & 469 & 595 & 0.260 & 4.185 & 1.085 & 0.544 & 4.185 & 1.085 & 0.544 \\
\hline 5 & 201 & 202 & 555 & 555 & 968 & 0.234 & 4.815 & -1.085 & 0.544 & 4.815 & -1.085 & 0.326 \\
\hline 6 & 201 & 202 & 469 & 469 & 595 & 0.260 & 4.815 & -1.085 & 0.544 & 4.815 & -1.085 & 0.326 \\
\hline 7 & 201 & 202 & 555 & 555 & 968 & 0.234 & 4.185 & -1.085 & 0.544 & 4.185 & -1.085 & 0.544 \\
\hline 8 & 201 & 202 & 469 & 469 & 595 & 0.260 & 4.185 & -1.085 & 0.544 & 4.185 & -1.085 & 0.544 \\
\hline 9 & 201 & 203 & 555 & 555 & 968 & 0.234 & 2.185 & 1.085 & 0.544 & 2.185 & 1.085 & 0.326 \\
\hline 10 & 201 & 203 & 469 & 469 & 595 & 0.260 & 2.185 & 1.085 & 0.544 & 2.185 & 1.085 & 0.326 \\
\hline 11 & 201 & 203 & 555 & 555 & 968 & 0.234 & 2.815 & 1.085 & 0.544 & 2.815 & 1.085 & 0.544 \\
\hline 12 & 201 & 203 & 469 & 469 & 595 & 0.260 & 2.815 & 1.085 & 0.544 & 2.815 & 1.085 & 0.544 \\
\hline 13 & 201 & 203 & 555 & 555 & 968 & 0.234 & 2.185 & -1.085 & 0.544 & 2.185 & -1.085 & 0.326 \\
\hline 14 & 201 & 203 & 469 & 469 & 595 & 0.260 & 2.185 & -1.085 & 0.544 & 2.185 & -1.085 & 0.326 \\
\hline 15 & 201 & 203 & 555 & 555 & 968 & 0.234 & 2.815 & -1.085 & 0.544 & 2.815 & -1.085 & 0.544 \\
\hline 16 & 201 & 203 & 469 & 469 & 595 & 0.260 & 2.815 & -1.085 & 0.544 & 2.815 & -1.085 & 0.544 \\
\hline
\end{tabular}


Table A.4 - Y21 front bogie: bumpstop elements of the PS.

\begin{tabular}{|c|c|c|c|c|c|c|c|c|c|c|}
\hline \multirow{3}{*}{$\begin{array}{c}\text { ID } \\
1\end{array}$} & \multicolumn{2}{|c|}{ Bodies } & \multirow{3}{*}{$\begin{array}{c}\text { Static preload } \\
{[\mathrm{kN}]}\end{array}$} & \multirow{3}{*}{$\begin{array}{c}\begin{array}{c}\text { Clearance } \\
{[\mathrm{mm}]}\end{array} \\
-\end{array}$} & \multirow{2}{*}{\multicolumn{3}{|c|}{$\begin{array}{c}\mathrm{P}_{i}\left(X_{0} / Y_{0} / H_{0}\right) \\
{[\mathrm{m}]}\end{array}$}} & \multirow{2}{*}{\multicolumn{3}{|c|}{$\begin{array}{c}\mathrm{P}_{j}\left(X_{0} / Y_{0} / H_{0}\right) \\
{[\mathrm{m}]}\end{array}$}} \\
\hline & \multirow{2}{*}{$\begin{array}{c}i \\
201\end{array}$} & \multirow{2}{*}{$\begin{array}{c}j \\
202\end{array}$} & & & & & & & & \\
\hline & & & & & 4.7 & 1.085 & 0.46 & 4.5 & 1.085 & 0.46 \\
\hline 2 & 201 & 202 & - & +4 & 4.3 & 1.085 & 0.46 & 4.5 & 1.085 & 0.46 \\
\hline 3 & 201 & 202 & - & \pm 10 & 4.5 & 0.985 & 0.46 & 4.5 & 1.185 & 0.46 \\
\hline 4 & 201 & 202 & 9.6 & - & 4.7 & -1.085 & 0.46 & 4.5 & -1.085 & 0.46 \\
\hline 5 & 201 & 202 & - & +4 & 4.3 & -1.085 & 0.46 & 4.5 & -1.085 & 0.46 \\
\hline 6 & 201 & 202 & - & \pm 10 & 4.5 & -0.985 & 0.46 & 4.5 & -1.185 & 0.46 \\
\hline 7 & 201 & 203 & 9.6 & - & 2.3 & 1.085 & 0.46 & 2.5 & 1.085 & 0.46 \\
\hline 8 & 201 & 203 & - & +4 & 2.7 & 1.085 & 0.46 & 2.5 & 1.085 & 0.46 \\
\hline 9 & 201 & 203 & - & \pm 10 & 2.5 & 0.985 & 0.46 & 2.5 & 1.185 & 0.46 \\
\hline 10 & 201 & 203 & 9.6 & - & 2.3 & -1.085 & 0.46 & 2.5 & -1.085 & 0.46 \\
\hline 11 & 201 & 203 & - & +4 & 2.7 & -1.085 & 0.46 & 2.5 & -1.085 & 0.46 \\
\hline 12 & 201 & 203 & - & \pm 10 & 2.5 & -0.985 & 0.46 & 2.5 & -1.185 & 0.46 \\
\hline
\end{tabular}

Note: the compression stiffness of the bumpstops is $60000 \mathrm{kN} / \mathrm{m}$. 
Table A.5 - Y21 front bogie: friction elements of the PS.

\begin{tabular}{|c|c|c|c|c|c|c|c|c|}
\hline \multirow{2}{*}{ ID } & \multicolumn{2}{|c|}{ Bodies } & \multicolumn{3}{c|}{$\mathrm{P}_{i}\left(X_{0} / Y_{0} / H_{0}\right)$} & \multicolumn{3}{c|}{$\mathrm{P}_{j}\left(X_{0} / Y_{0} / H_{0}\right)$} \\
\cline { 2 - 8 } & $i$ & $j$ & \multicolumn{3}{|c|}{$[\mathrm{m}]$} \\
\hline 11 & 201 & 202 & 4.6 & 1.085 & 0.56 & 4.6 & 1.085 & 0.36 \\
\hline 12 & 201 & 202 & 4.6 & 1.185 & 0.46 & 4.6 & 0.985 & 0.46 \\
\hline 21 & 201 & 202 & 4.4 & 1.085 & 0.56 & 4.4 & 1.085 & 0.56 \\
\hline 22 & 201 & 202 & 4.4 & 1.185 & 0.46 & 4.4 & 1.185 & 0.46 \\
\hline 31 & 201 & 202 & 4.6 & -1.085 & 0.56 & 4.6 & -1.085 & 0.36 \\
\hline 32 & 201 & 202 & 4.6 & -1.185 & 0.46 & 4.6 & -0.985 & 0.46 \\
\hline 41 & 201 & 202 & 4.4 & -1.085 & 0.56 & 4.4 & -1.085 & 0.56 \\
\hline 42 & 201 & 202 & 4.4 & -1.185 & 0.46 & 4.4 & -1.185 & 0.46 \\
\hline 51 & 201 & 203 & 2.4 & 1.085 & 0.56 & 2.4 & 1.085 & 0.36 \\
\hline 52 & 201 & 203 & 2.4 & 1.185 & 0.46 & 2.4 & 0.985 & 0.46 \\
\hline 61 & 201 & 203 & 2.6 & 1.085 & 0.56 & 2.6 & 1.085 & 0.56 \\
\hline 62 & 201 & 203 & 2.6 & 1.185 & 0.46 & 2.6 & 1.185 & 0.46 \\
\hline 71 & 201 & 203 & 2.4 & -1.085 & 0.56 & 2.4 & -1.085 & 0.36 \\
\hline 72 & 201 & 203 & 2.4 & -1.185 & 0.46 & 2.4 & -0.985 & 0.46 \\
\hline 81 & 201 & 203 & 2.6 & -1.085 & 0.56 & 2.6 & -1.085 & 0.56 \\
\hline 82 & 201 & 203 & 2.6 & -1.185 & 0.46 & 2.6 & -1.185 & 0.46 \\
\hline
\end{tabular}

Note: the static normal force acting on the friction surfaces is equal to the static preload on the respective bumpstops, i.e., $9.6 \mathrm{kN}$. The dynamic components of the normal force are equal to the sum of the dynamic load on the associated shear spring multiplied by a factor of $\tan \left(21^{\circ}\right)$, plus the dynamic load on the respective bumpstops. The friction coefficient considered in the friction surfaces of the PS is 0.4 . 
Table A.6 - Secondary suspension: bumpstop elements associated to the side bearers.

\begin{tabular}{|c|c|c|c|c|c|c|c|c|c|c|c|}
\hline \multirow{3}{*}{$\begin{array}{l}\text { ID } \\
1\end{array}$} & \multicolumn{2}{|c|}{ Bodies } & \multirow{3}{*}{$\begin{array}{c}\text { Static preload } \\
{[\mathrm{kN}]} \\
-\end{array}$} & \multirow{3}{*}{$\begin{array}{c}\begin{array}{c}\text { Clearance } \\
{[\mathrm{mm}]}\end{array} \\
\pm 1\end{array}$} & \multirow{3}{*}{$\begin{array}{c}\text { Spring stiffness } k_{\mathrm{Z}} \\
{[\mathrm{kN} / \mathrm{m}]}\end{array}$} & \multirow{2}{*}{\multicolumn{3}{|c|}{$\begin{array}{c}\mathrm{P}_{i}\left(X_{0} / Y_{0} / H_{0}\right) \\
{[\mathrm{m}]}\end{array}$}} & \multirow{2}{*}{\multicolumn{3}{|c|}{$\begin{array}{c}\mathrm{P}_{j}\left(X_{0} / Y_{0} / H_{0}\right) \\
{[\mathrm{m}]}\end{array}$}} \\
\hline & \multirow{2}{*}{$\frac{i}{201}$} & \multirow{2}{*}{$\frac{j}{204}$} & & & & & & & & & \\
\hline & & & & & & 3.3 & 0.85 & 0.896 & 3.7 & 0.85 & 0.896 \\
\hline 2 & 201 & 101 & 16 & +40 & 570 & 3.5 & 0.85 & 0.700 & 3.5 & 0.85 & 0.890 \\
\hline 3 & 201 & 205 & - & \pm 1 & - & 3.3 & -0.85 & 0.896 & 3.7 & -0.85 & 0.896 \\
\hline 4 & 201 & 101 & 16 & +40 & 570 & 3.5 & -0.85 & 0.700 & 3.5 & -0.85 & 0.890 \\
\hline
\end{tabular}

Note: the compression stiffness of the bumpstops is $60000 \mathrm{kN} / \mathrm{m}$. However, bumpstop elements

2 and 4 in the SS present the spring stiffness $k_{\mathrm{Z}}$ for values of deflection to compression smaller than $40 \mathrm{~mm}$. 
Table A.7 - Secondary suspension: friction elements associated to the side bearers.

\begin{tabular}{|c|c|c|c|c|c|c|c|c|}
\hline \multirow{2}{*}{ ID } & \multicolumn{2}{|c|}{ Bodies } & \multicolumn{3}{c|}{$\mathrm{P}_{i}\left(X_{0} / Y_{0} / H_{0}\right)$} & \multicolumn{3}{c|}{$\mathrm{P}_{j}\left(X_{0} / Y_{0} / H_{0}\right)$} \\
\cline { 2 - 9 } & $i$ & $j$ & \multicolumn{3}{|c|}{$[\mathrm{m}]$} & \multicolumn{3}{|c|}{$[\mathrm{m}]$} \\
\hline 1 & 204 & 101 & 3.7 & 0.85 & 0.896 & 3.3 & 0.85 & 0.896 \\
\hline 2 & 205 & 101 & 3.7 & 0.85 & 0.896 & 3.3 & 0.85 & 0.896 \\
\hline
\end{tabular}

Note: the static normal force acting on the friction surfaces is equal to the static preload on the respective vertical bumpstops, i.e., $16 \mathrm{kN}$. The dynamic component of the normal force is equal to the dynamic load on the bumpstops. The friction coefficient considered in the friction surfaces of the side bearers is 0.3 . 
Table A.8 - Secondary suspension: elastic elements of the pivot.

\begin{tabular}{|c|c|c|c|c|c|c|c|c|c|c|c|}
\hline \multirow{3}{*}{$\begin{array}{c}\text { ID } \\
1\end{array}$} & \multicolumn{2}{|c|}{ Bodies } & \multirow{2}{*}{\multicolumn{3}{|c|}{$\begin{array}{c}\text { Stiffness }\left(k_{\mathrm{X}} / k_{\mathrm{Y}} / k_{\mathrm{Z}}\right) \\
{[\mathrm{kNN} / \mathrm{m}]}\end{array}$}} & \multirow{2}{*}{\multicolumn{3}{|c|}{$\begin{array}{c}\mathrm{P}_{i}\left(X_{0} / Y_{0} / H_{0}\right) \\
{[\mathrm{m}]}\end{array}$}} & \multirow{2}{*}{\multicolumn{3}{|c|}{$\begin{array}{c}\mathrm{P}_{j}\left(X_{0} / Y_{0} / H_{0}\right) \\
{[\mathrm{m}]}\end{array}$}} \\
\hline & $i$ & $j$ & & & & & & & & & \\
\hline & 201 & 101 & 60000 & 60000 & 0 & 3.5 & 0 & 0.739 & 3.5 & 0 & 0.739 \\
\hline 2 & 201 & 101 & - & - & 60000 & 3.5 & 0 & 0.689 & 3.5 & 0 & 0.780 \\
\hline
\end{tabular}

Note: element 1 is a bush element, while element 2 is a stiffness element. 
Table A.9 - Secondary suspension: friction elements associated to the pivot.

\begin{tabular}{|c|c|c|c|c|c|c|c|c|}
\hline \multirow{3}{*}{$\begin{array}{l}\text { ID } \\
11\end{array}$} & \multicolumn{2}{|c|}{ Bodies } & \multirow{2}{*}{\multicolumn{3}{|c|}{$\begin{array}{c}\mathrm{P}_{i}\left(X_{0} / Y_{0} / H_{0}\right) \\
{[\mathrm{m}]}\end{array}$}} & \multirow{2}{*}{\multicolumn{3}{|c|}{$\begin{array}{c}\mathrm{P}_{j}\left(X_{0} / Y_{0} / H_{0}\right) \\
{[\mathrm{m}]}\end{array}$}} \\
\hline & \multirow{2}{*}{$\begin{array}{c}i \\
201\end{array}$} & \multirow{2}{*}{$\begin{array}{c}j \\
101\end{array}$} & & & & & & \\
\hline & & & 3.69 & 0 & 0.839 & 3.69 & 0 & 0.639 \\
\hline 12 & 201 & 101 & 3.69 & 0.1 & 0.739 & 3.69 & -0.1 & 0.739 \\
\hline 21 & 201 & 101 & 3.5 & 0.19 & 0.839 & 3.5 & 0.19 & 0.639 \\
\hline 22 & 201 & 101 & 3.6 & 0.19 & 0.739 & 3.4 & 0.19 & 0.739 \\
\hline 31 & 201 & 101 & 3.31 & 0 & 0.839 & 3.31 & 0 & 0.639 \\
\hline 32 & 201 & 101 & 3.31 & 0.1 & 0.739 & 3.31 & -0.1 & 0.739 \\
\hline 41 & 201 & 101 & 3.5 & -0.19 & 0.839 & 3.5 & -0.19 & 0.639 \\
\hline 42 & 201 & 101 & 3.6 & -0.19 & 0.739 & 3.4 & -0.19 & 0.739 \\
\hline
\end{tabular}

Note: the static normal force acting on the friction surfaces is equal to a quarter of the static preload on the stiffness element of the pivot, i.e., $67.85 \mathrm{kN}$. The dynamic component of the normal force is equal to the dynamic load on the stiffness element. The friction coefficient considered in the friction surfaces of the pivot is 0.3 . 
Table 1 - Main characteristics of the Shimms wagon.

\begin{tabular}{ll}
\hline Track gauge & $1.668 \mathrm{~m}$ (Iberian) \\
Wheel diameter (new condition) & $0.920 \mathrm{~m}$ \\
Wheelset rolling line distance & $1.735 \mathrm{~m}$ \\
Wheelset weight (including axleboxes) & $1.44 \mathrm{t}$ (approx.) \\
Bogie weight (including wheelsets, axleboxes, braking gear, etc) & $4.8 \mathrm{t} \mathrm{(approx.)}$ \\
Vehicle body weight (tare) & $14.1 \mathrm{t}$ (approx.) \\
Maximum payload & $56.3 \mathrm{t}$ \\
Bogie wheelbase & $2 \mathrm{~m}$ \\
Bogie centre distance & $7 \mathrm{~m}$ \\
Vehicle length (including buffers) & $12.04 \mathrm{~m}$ \\
Maximum service speed (laden) & $100 \mathrm{~km} / \mathrm{h}$ \\
\hline
\end{tabular}


Table 2 - Design variables and the respective range of variation used in the different scenarios.

\begin{tabular}{cccccc}
\hline Variable & Description & Min. value & Central value & Max. value & Observation \\
\hline$t_{1}$ & Lat. deviation cargo [m] & -0.08 & 0 & 0.08 & \\
$t_{2}$ & Braking moment [kN.m] & 0 & 4 & 8 & \\
$t_{3}$ & Vehicle speed [km/h] & 90 & 100 & 110 & \\
$t_{4}$ & Lenoir link failure & n.a. & n.a. & n.a. & None, W2R, W4R \\
\hline
\end{tabular}


Table 3 - Conversion between coded variables and design variables.

\begin{tabular}{cccccc}
\hline$x_{\mathrm{i}}$ & -1.682 & -1.0000 & 0.0000 & 1.0000 & 1.682 \\
\hline$t_{1}[\mathrm{~m}]$ & -0.080 & -0.048 & 0.000 & 0.048 & 0.080 \\
$t_{2}[\mathrm{kN} . \mathrm{m}]$ & 0.000 & 1.622 & 4.000 & 6.378 & 8.000 \\
$t_{3}[\mathrm{~km} / \mathrm{h}]$ & 90 & 94 & 100 & 106 & 110 \\
\hline
\end{tabular}


Table 4 - Values of the design variables of the computer experiments.

\begin{tabular}{|c|c|c|c|}
\hline Simulation ID & $\begin{array}{l}\text { Lateral deviation cargo } \\
\qquad[\mathrm{m}]\end{array}$ & $\begin{array}{l}\text { Braking moment } \\
{[\mathrm{kN} . \mathrm{m}]}\end{array}$ & $\begin{array}{c}\text { Vehicle speed } \\
{[\mathrm{km} / \mathrm{h}]}\end{array}$ \\
\hline $01 / 16 / 31$ & -0.048 & 1.622 & 94 \\
\hline $02 / 17 / 32$ & 0.048 & 1.622 & 94 \\
\hline $03 / 18 / 33$ & -0.048 & 6.378 & 94 \\
\hline $04 / 19$ / 34 & 0.048 & 6.378 & 94 \\
\hline $05 / 20 / 35$ & -0.048 & 1.622 & 106 \\
\hline $06 / 21 / 36$ & 0.048 & 1.622 & 106 \\
\hline $07 / 22 / 37$ & -0.048 & 6.378 & 106 \\
\hline $08 / 23 / 38$ & 0.048 & 6.378 & 106 \\
\hline $09 / 24$ / 39 & -0.080 & 4.000 & 100 \\
\hline $10 / 25 / 40$ & 0.080 & 4.000 & 100 \\
\hline $11 / 26 / 41$ & 0.000 & 0.000 & 100 \\
\hline $12 / 27 / 42$ & 0.000 & 8.000 & 100 \\
\hline $13 / 28 / 43$ & 0.000 & 4.000 & 90 \\
\hline $14 / 29 / 44$ & 0.000 & 0.000 & 110 \\
\hline $15 / 30 / 45$ & 0.000 & 8.000 & 100 \\
\hline
\end{tabular}


Table 5 - Maximum values of $Y / Q$ and $\Delta Q / Q_{0}$ on wheel W3L predicted using the response surfaces.

\begin{tabular}{|c|c|c|c|c|c|c|c|}
\hline & $f(\mathbf{t})$ & & $\begin{array}{l}\text { Lat. deviation cargo } \\
\qquad[\mathrm{m}]\end{array}$ & $\begin{array}{c}\text { Braking moment } \\
{[\mathrm{kN} . \mathrm{m}]}\end{array}$ & $\begin{array}{l}\text { Speed } \\
{[\mathrm{km} / \mathrm{h}]}\end{array}$ & $\begin{array}{c}\text { Max } \\
\text { Resp. Surface }\end{array}$ & $\begin{array}{l}\text { Significant } \\
\text { coefficients }\end{array}$ \\
\hline \multirow{6}{*}{ Nominal } & $Y$ & $1 \mathrm{R}$ & -0.08 & & 110 & 0.701 & $\beta_{0}, \beta_{1}, \beta_{3}$ \\
\hline & $\bar{Q}$ & $3 R$ & -0.08 & & 110 & 0.744 & $\beta_{0}, \beta_{1}, \beta_{3}$ \\
\hline & & $1 \mathrm{~L}$ & 0.08 & & 110 & 0.543 & $\beta_{0}, \beta_{1}, \beta_{3}$ \\
\hline & $\Delta Q$ & $2 \mathrm{~L}$ & 0.08 & & 110 & 0.427 & $\beta_{0}, \beta_{1}, \beta_{3}$ \\
\hline & $\overline{Q_{0}}$ & $3 \mathrm{~L}$ & 0.08 & & 110 & 0.723 & $\beta_{0}, \beta_{1}, \beta_{3}$ \\
\hline & & $4 \mathrm{~L}$ & 0.08 & & 110 & 0.648 & $\beta_{0}, \beta_{1}, \beta_{3}$ \\
\hline \multirow{6}{*}{$\begin{array}{l}\text { Lenoir } \\
\text { failure } \\
\text { W2R }\end{array}$} & $Y$ & $1 \mathrm{R}$ & -0.08 & & 110 & 0.669 & $\beta_{0}, \beta_{1}, \beta_{3}$ \\
\hline & $\bar{Q}$ & $3 R$ & -0.08 & & 110 & 0.735 & $\beta_{0}, \beta_{1}, \beta_{3}$ \\
\hline & & $1 \mathrm{~L}$ & 0.08 & & 110 & 0.533 & $\beta_{0}, \beta_{3}$ \\
\hline & $\Delta Q$ & $2 \mathrm{~L}$ & 0.08 & 4 & 110 & 0.386 & $\beta_{0}, \beta_{1}, \beta_{2}, \beta_{3}$ \\
\hline & $\overline{Q_{0}}$ & $3 \mathrm{~L}$ & 0.08 & & 110 & 0.773 & $\beta_{0}, \beta_{1}, \beta_{3}$ \\
\hline & & $4 \mathrm{~L}$ & 0.08 & & 110 & 0.690 & $\beta_{0}, \beta_{1}, \beta_{3}$ \\
\hline \multirow{6}{*}{$\begin{array}{l}\text { Lenoir } \\
\text { failure } \\
\text { W4R }\end{array}$} & $\underline{Y}$ & $1 \mathrm{R}$ & -0.08 & & 110 & 0.700 & $\beta_{0}, \beta_{1}, \beta_{3}$ \\
\hline & $\bar{Q}$ & $3 \mathrm{R}$ & -0.08 & & 110 & 0.727 & $\beta_{0}, \beta_{1}, \beta_{3}$ \\
\hline & & $1 \mathrm{~L}$ & 0.08 & & 110 & 0.550 & $\beta_{0}, \beta_{3}$ \\
\hline & $\Delta Q$ & $2 \mathrm{~L}$ & 0.08 & & 110 & 0.446 & $\beta_{0}, \beta_{1}, \beta_{3}$ \\
\hline & $\overline{Q_{0}}$ & $3 \mathrm{~L}$ & 0.08 & & 110 & 0.758 & $\beta_{0}, \beta_{1}, \beta_{3}$ \\
\hline & & $4 \mathrm{~L}$ & 0.08 & & 110 & 0.609 & $\beta_{0}, \beta_{1}, \beta_{3}$ \\
\hline
\end{tabular}


Table 6 - Values of the significance tests for the regressions and respective regressors of $\Delta Q / Q_{0}$ on wheel W3L without Lenoir link failure.

\begin{tabular}{cccccc}
\hline Source & D.o.f. & Sum of squares & Mean squares & $F_{0}$ & $P$-value \\
\hline Regression & 2 & 0.093118 & 0.046559 & 701.184650 & $<0.01$ \\
Residual & 12 & 0.000797 & $6.640052 \mathrm{e}-05$ & & \\
Total & 14 & 0.093915 & & & \\
\hline \multicolumn{7}{c}{} \\
\hline Predictor & Coef. & Std. Dev. & $t_{0}$ & $P$-value & \\
\hline$t_{1}$ & 0.532843 & 0.002104 & 253.255654 & $<0.01$ & \\
$t_{3}$ & 0.041371 & 0.002205 & 18.762471 & $<0.01$ & \\
\hline
\end{tabular}


Table 7 - Values of the significance tests for the regressions and respective regressors of $\Delta Q / Q_{0}$ on wheel W3L with Lenoir link failure on wheel W2R.

\begin{tabular}{cccccc}
\hline Source & D.o.f. & Sum of squares & Mean squares & $F_{0}$ & $P$-value \\
\hline Regression & 2 & 0.116736 & 0.058368 & 239.651972 & $<0.01$ \\
Residual & 12 & 0.002923 & 0.000244 & & \\
Total & 14 & 0.119659 & & & \\
\hline \multicolumn{7}{c}{} & & & & \\
\hline Predictor & Coef. & Std. Dev. & $t_{0}$ & $P$-value & \\
\hline$t_{1}$ & 0.557167 & 0.004029 & 138.272087 & $<0.01$ & \\
$t_{3}$ & 0.052395 & 0.004223 & 12.407108 & $<0.01$ & \\
\hline
\end{tabular}


Table 8 - Values of the significance tests for the regressions and respective regressors of $\Delta \mathrm{Q} / \mathrm{Q} 0$ on wheel W3L with Lenoir link failure on wheel W4R.

\begin{tabular}{cccccc}
\hline Source & D.o.f. & Sum of squares & Mean squares & $F_{0}$ & $P$-value \\
\hline Regression & 2 & 0.066928 & 0.033464 & 487.404584 & $<0.01$ \\
Residual & 12 & 0.000824 & $6.865705 \mathrm{e}-05$ & & \\
Total & 14 & 0.067751 & & & \\
\hline \multicolumn{7}{c}{} & & & & \\
\hline Predictor & Coef. & Std. Dev. & $t_{0}$ & $P$-value & \\
\hline$t_{1}$ & 0.593419 & 0.002139 & 277.373379 & $<0.01$ & \\
$t_{3}$ & 0.040926 & 0.002242 & 18.252936 & $<0.01$ & \\
\hline
\end{tabular}


Table 9 - Comparison of maximum values of $\Delta Q / Q_{0}$ on wheel W3L predicted using the response surfaces and using VAMPIRE.

\begin{tabular}{cccccc}
\hline & $\begin{array}{c}\text { Lateral deviation cargo } \\
{[\mathrm{m}]}\end{array}$ & $\begin{array}{c}\text { Speed } \\
{[\mathrm{km} / \mathrm{h}]}\end{array}$ & $\begin{array}{c}\text { Max } \\
\text { Response Surface }\end{array}$ & $\begin{array}{c}\text { Max } \\
\text { VAMPIRE }\end{array}$ & $\begin{array}{c}\text { Relative } \\
\text { difference }\end{array}$ \\
\hline Nominal & 0.08 & 110 & 0.723 & 0.706 & $+2.4 \%$ \\
Lenoir failure W2R & 0.08 & 110 & 0.773 & 0.741 & $+4.3 \%$ \\
Lenoir failure W4R & 0.08 & 110 & 0.758 & 0.763 & $-0.7 \%$ \\
\hline
\end{tabular}



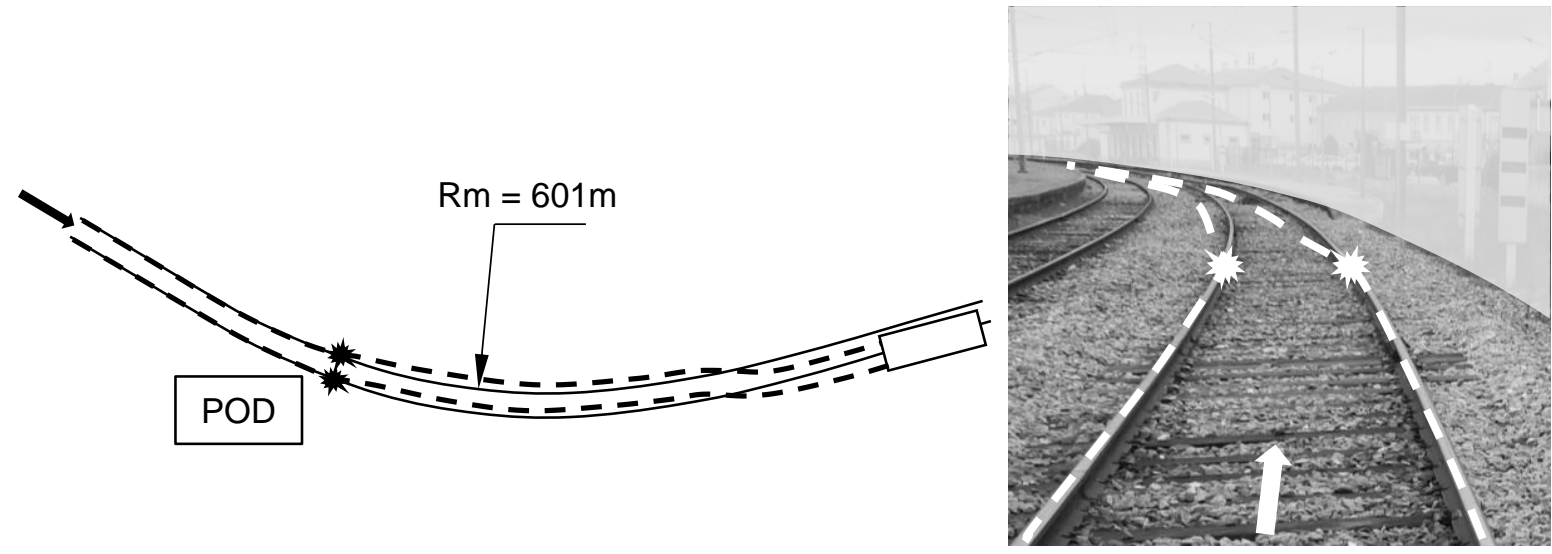

(a)

(b)

Figure 1 - Trajectory of the derailed wagon: (a) plan view; and (b) perspective on the full curved section. 

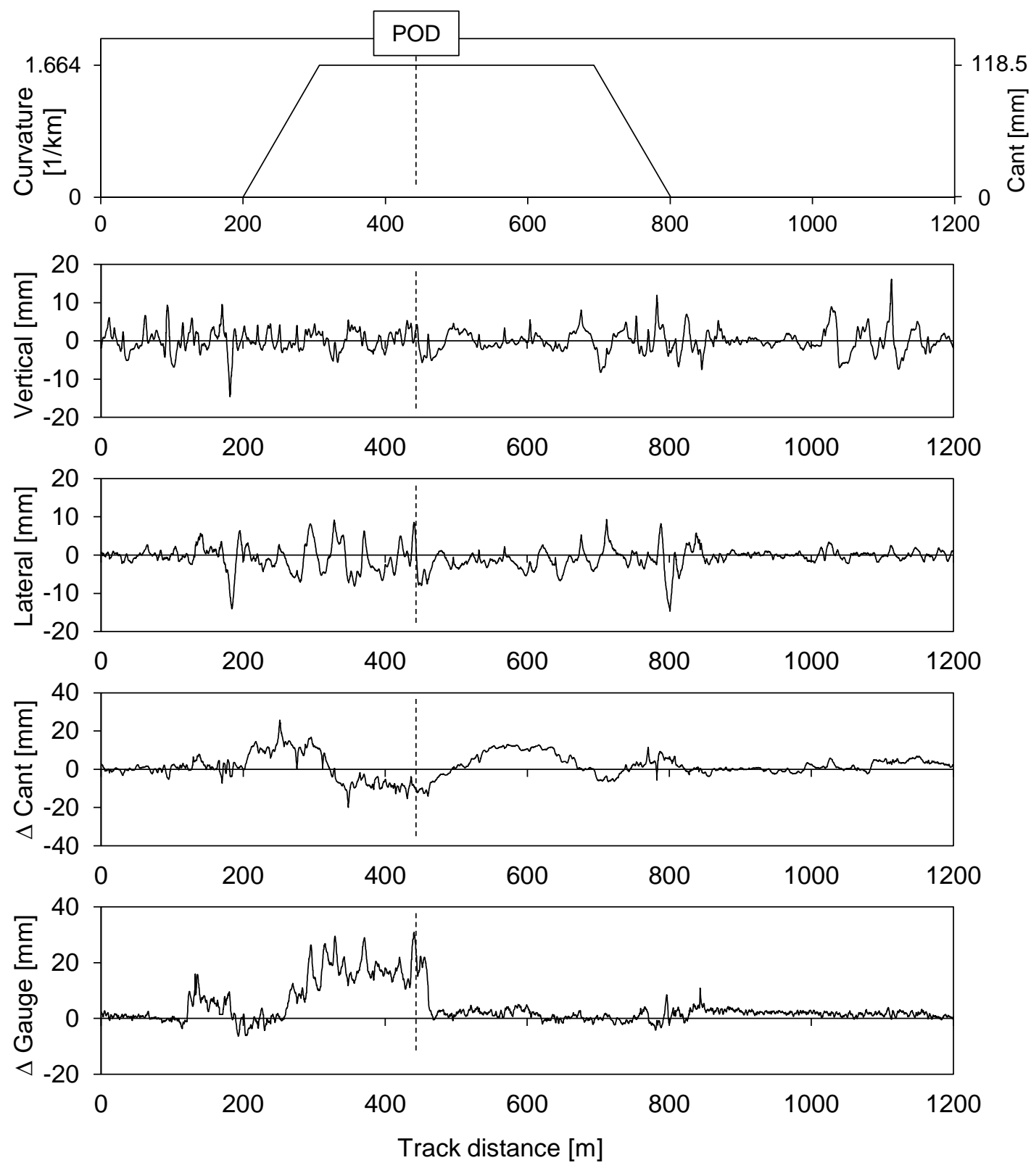

Figure 2 - Track layout and track irregularities with indication of the Position of Derailment (POD). 

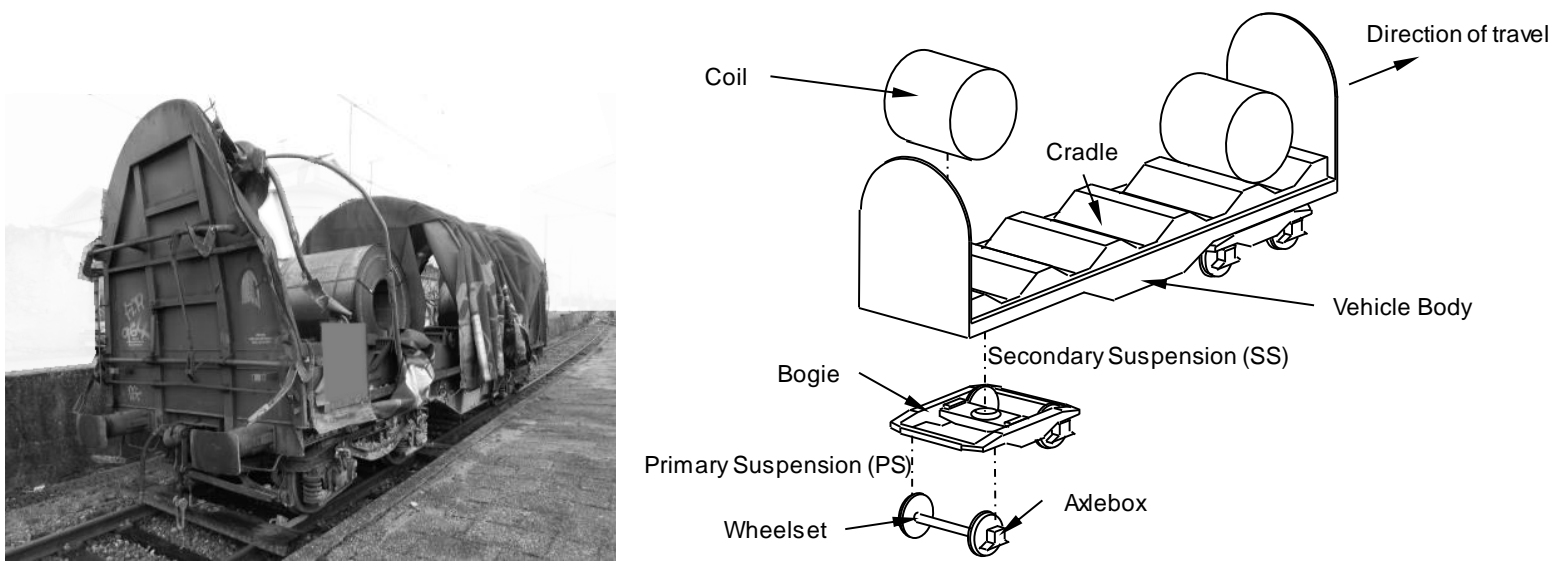

Figure 3 - Perspective of the damaged Shimms wagon and schematic representation of the structure of the vehicle. 


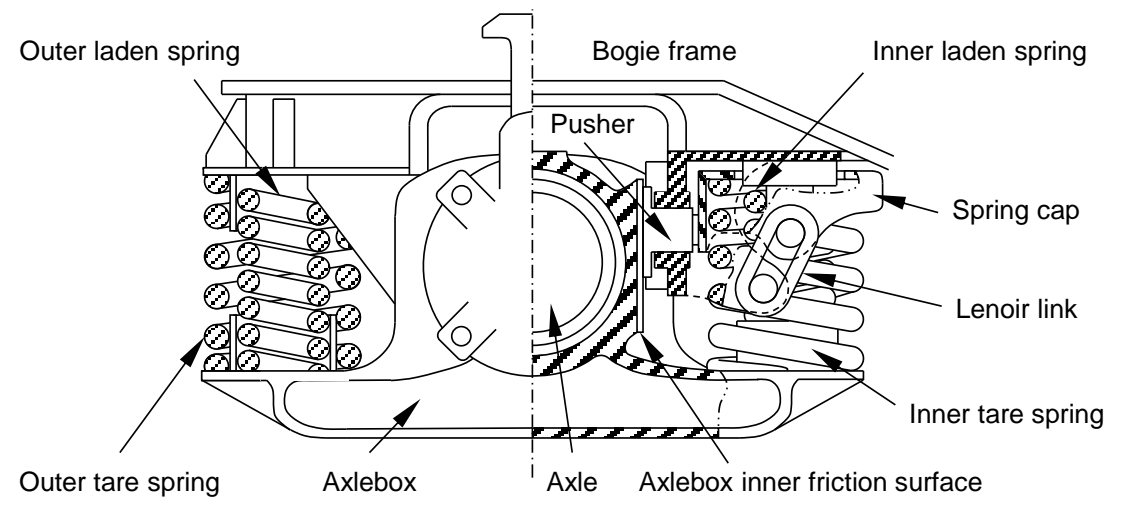

(a)

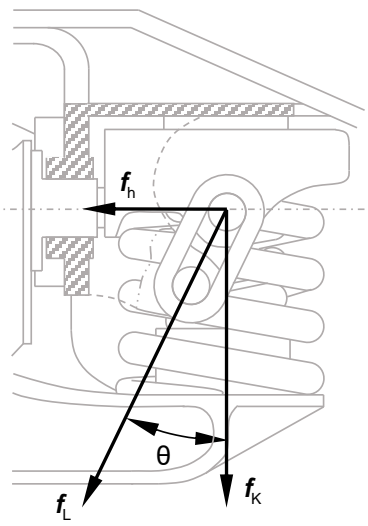

(b)

Figure 4 - Schematic representation of the PS of the Y21 bogie: (a) side view and (b) force decomposition associated with the Lenoir link. 


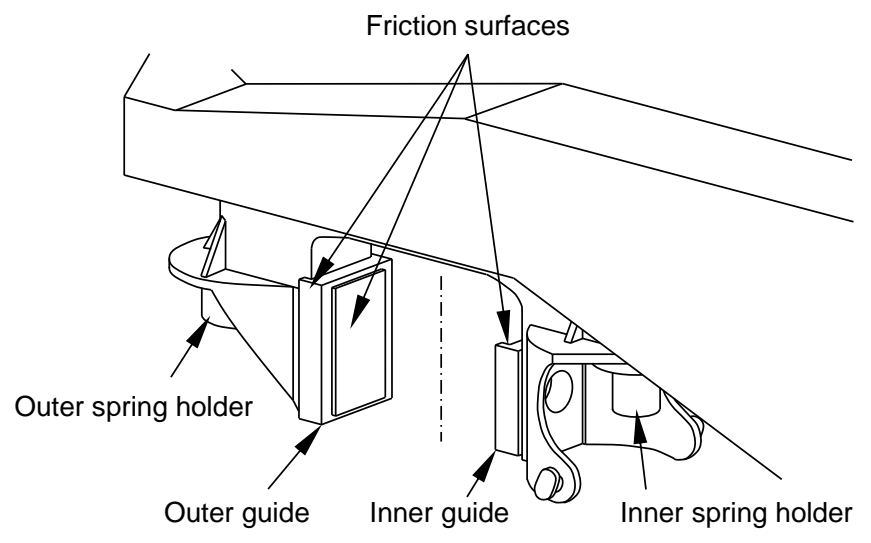

(a)

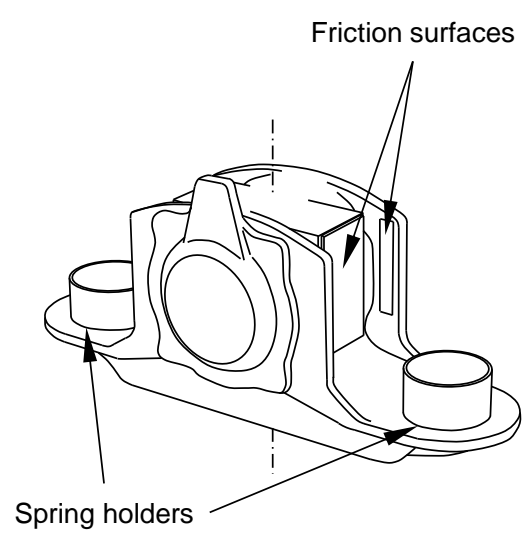

(b)

Figure 5 - Schematic representation of (a) bogie frame guides of the PS and (b) axlebox. 


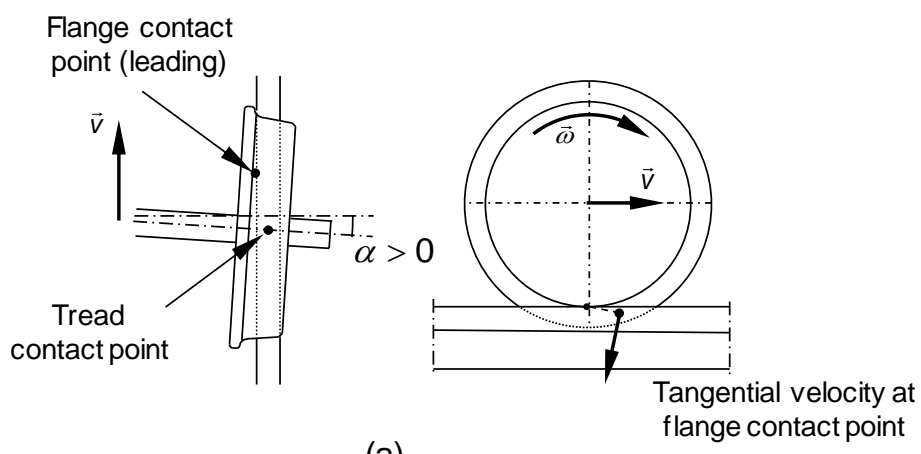

(a)

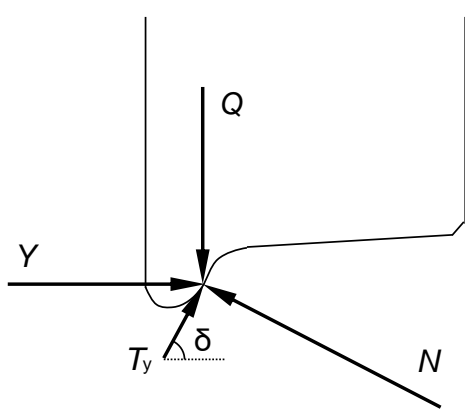

(b)

Figure 6 - Schematic representation of: (a) top and side view of the flanging wheel, and (b) forces at the flange contact point. 


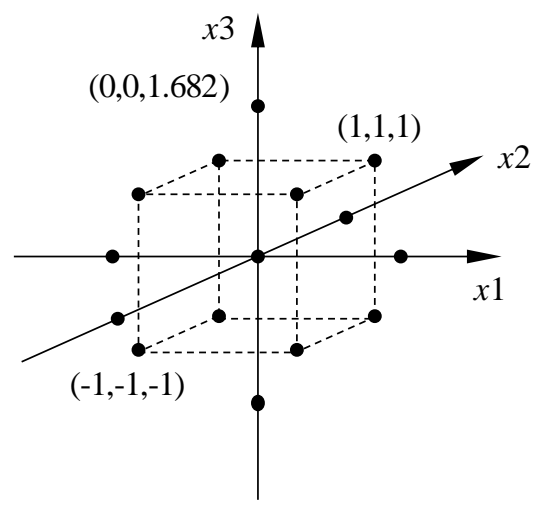

Figure 7 - Central composite design with $k=3$ design variables. 

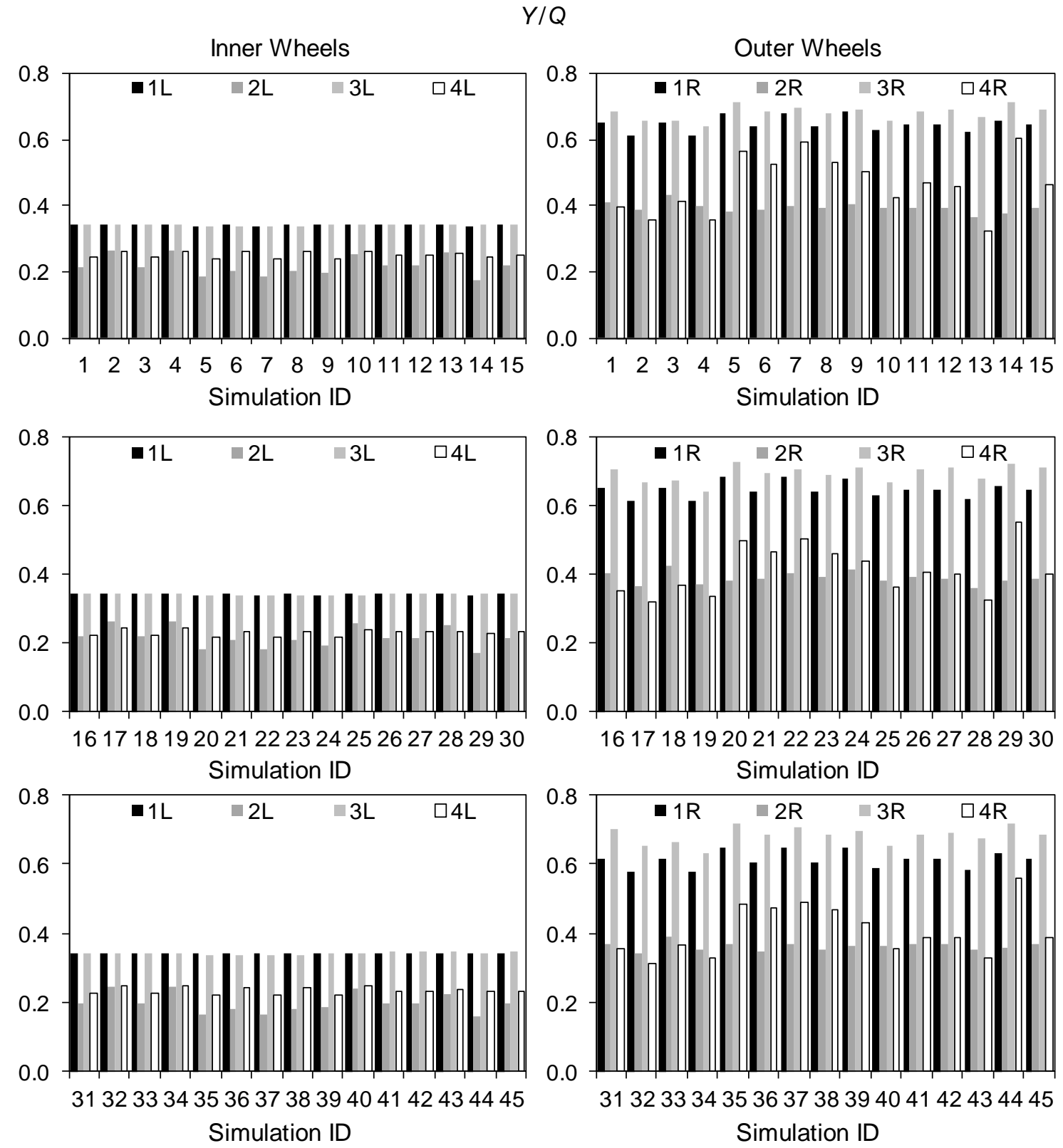

Figure 8 - Maximum values of $Y / Q$ obtained from the VAMPIRE simulations. 

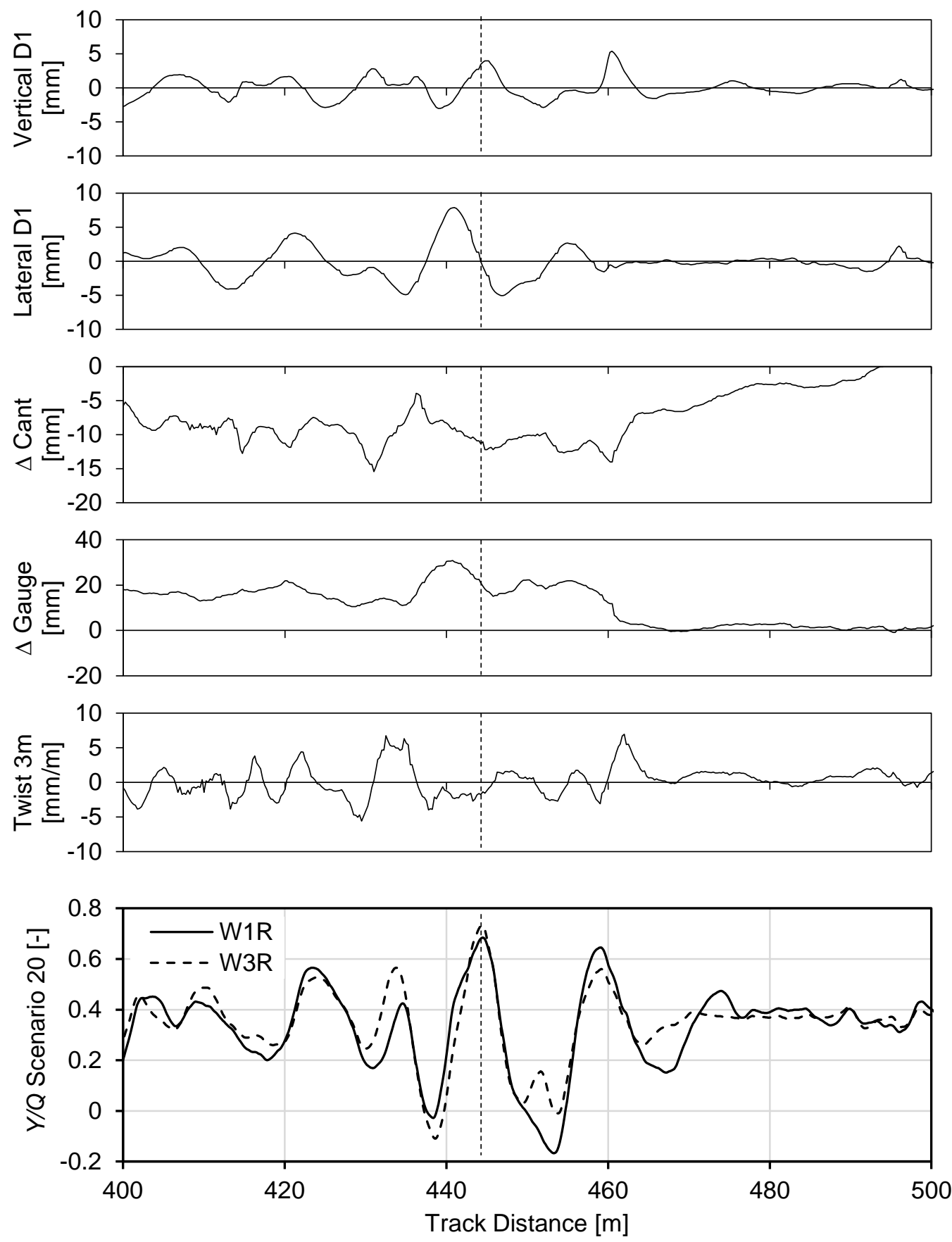

Figure 9 - Track irregularities and $Y / Q$ results on wheels W1R and W3R from scenario 20. 

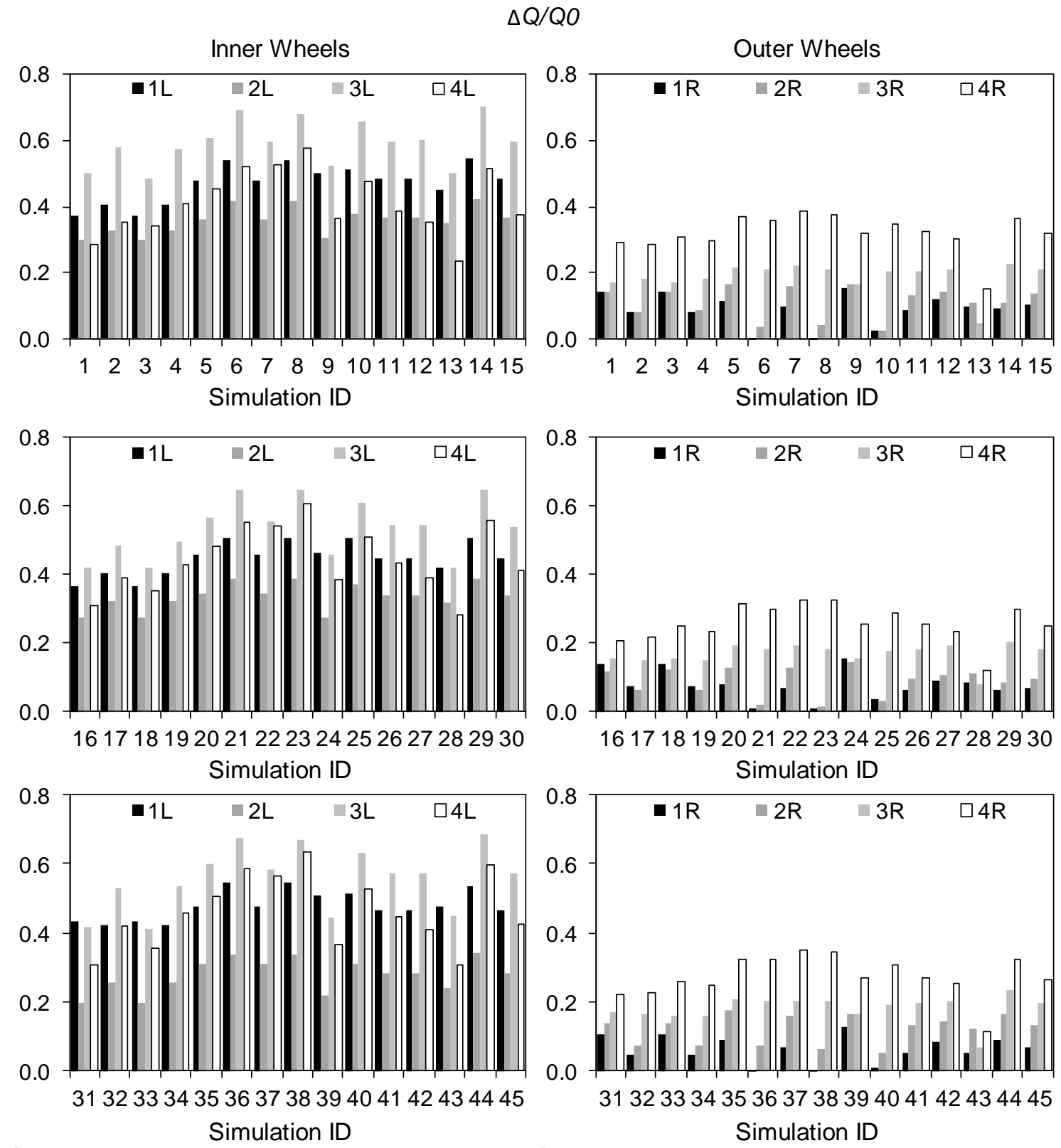

Figure 10 - Maximum values of $\Delta Q / Q_{0}$ obtained from the VAMPIRE simulations. 


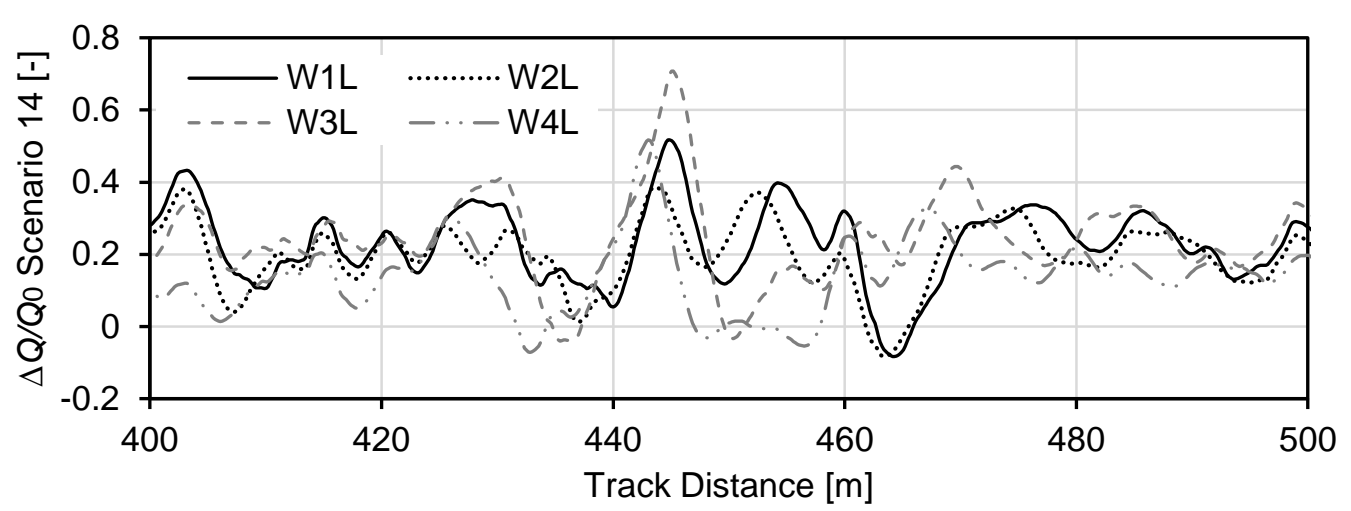

Figure $11-\Delta Q / Q_{0}$ results on wheels W1L, W2L, W3L and W4L from scenario 14. 

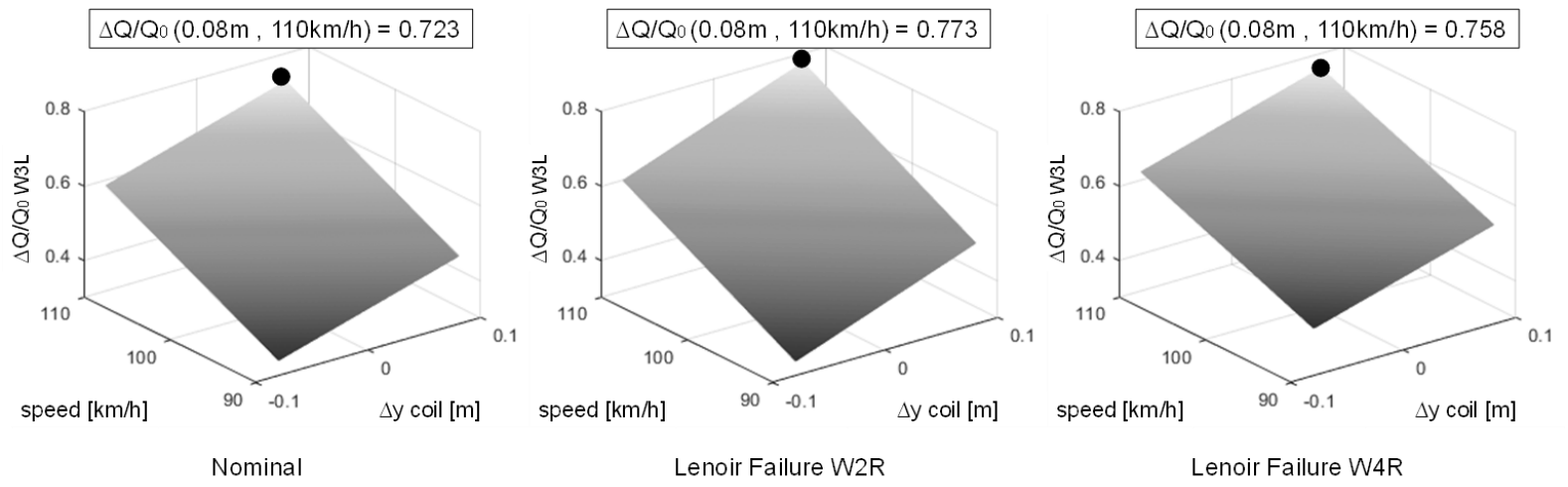

Figure $12-\Delta Q / Q_{0}$ on wheel W3L as a function of the design variables $t_{1}$ and $t_{3}$, and Lenoir link condition. 


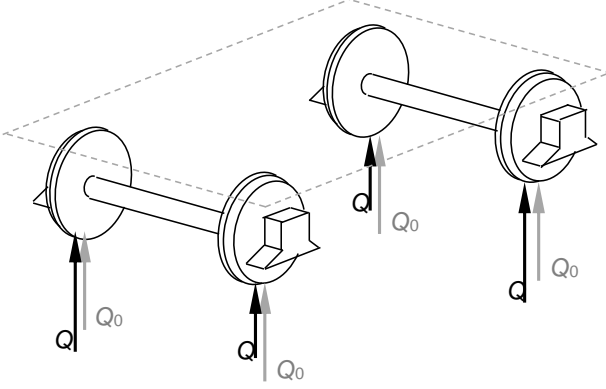

Figure 13 - Schematic representation of the redistribution of vertical wheel load on the wheels of a bogie, caused by the failure of a suspension element. 